Florida International University

FIU Digital Commons

3-5-2002

\title{
Interprofessional perceptions between occupational therapists and physical therapists: barriers to effective interdisciplinary team functioning
}

Jennifer L. Gober

Florida International University

Follow this and additional works at: https://digitalcommons.fiu.edu/etd

Part of the Occupational Therapy Commons, and the Physical Therapy Commons

\section{Recommended Citation}

Gober, Jennifer L., "Interprofessional perceptions between occupational therapists and physical therapists: barriers to effective interdisciplinary team functioning" (2002). FIU Electronic Theses and Dissertations. 4002.

https://digitalcommons.fiu.edu/etd/4002

This work is brought to you for free and open access by the University Graduate School at FIU Digital Commons. It has been accepted for inclusion in FIU Electronic Theses and Dissertations by an authorized administrator of FIU Digital Commons. For more information, please contact dcc@fiu.edu. 
FLORIDA INTERNATIONAL UNIVERSITY

Miami, Florida

INTERPROFESSIONAL PERCEPTIONS BETWEEN OCCUPATIONAL THERAPISTS AND PHYSICAL THERAPISTS: BARRIERS TO EFFECTIVE INTERDISCIPLINARY TEAM FUNCTIONING

A thesis submitted in partial fulfillment of the

requirements for the degree of

MASTER OF SCIENCE

in

OCCUPATIONAL THERAPY

by

Jennifer L. Gober

2002 
To: Dean Ronald M. Berkman

College of Health and Urban Affairs

This thesis, written by Jennifer L. Gober, and entitled Interprofessional Perceptions Between Occupational Therapists and Physical Therapists: Barriers to Effective Interdisciplinary Team Functioning, having been approved in respect to style and intellectual content, is referred to you for judgment.

We have read this thesis and recommend that it be approved.

Shusan D'Agati

Agnes Sheffey

Susan Kaplan, Major Professor

Date of Defense: March 5, 2002

The thesis of Jennifer L. Gober is approved.

Dean Ronald M. Berkman

College of Health and Urban Affairs

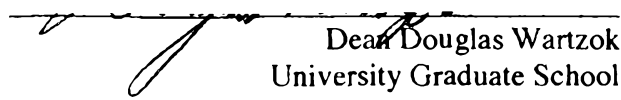

Florida International University, 2002 


\section{DEDICATION}

I dedicate this thesis to the loving memory of my mom for her ongoing love, encouragement, and support throughout the years. But most importantly for her teaching me to believe in myself and that no dream was impossible to reach. 


\section{ACKNOWLEDGMENTS}

I wish to thank all the members of my committee, Dr. Susan Kaplan, Dr. Sue D'Agati, and Dr. Agnes Sheffey for their time, suggestions, and guidance.

I would like to extend a special thank you to Jorge Moreno from statistical consulting and Dr. Paulette Johnson for taking the time to help me with the data analysis.

For the ongoing support of my classmates throughout this endeavor, a very special thank you is extended to Debbie, Annabel, Ana, Paola, and Danny.

I also want thank my sister, Debi, for her words of encouragement and wisdom.

Finally, a thank you may not be nearly enough but is extended to Mike for his unconditional love, words of advice, and ongoing support throughout the pursuit of my educational goals. 


\section{ABSTRACT OF THE THESIS \\ INTERPROFESSIONAL PERCEPTIONS BETWEEN OCCUPATIONAL \\ THERAPISTS AND PHYSICAL THERAPISTS: BARRIERS TO EFFECTIVE \\ INTERDISCIPLINARY TEAM FUNCTIONING}

by

Jennifer L. Gober

Florida International University, 2002

Miami, Florida

Professor Susan Kaplan, Major Professor

OT and PT practitioners are expected to function as members of an interdisciplinary team effectively. It is important to be aware of the barriers that may create conflict between them. The purpose of this study was to examine interprofessional perceptions regarding interprofessional and practice issues that might serve as barriers to effective interdisciplinary team functioning. A random sample of 400 therapists (200 OTs and 200 PTs) was mailed questionnaires. A total of 182 questionnaires were used for data analysis. Research questions were analyzed using descriptive statistics, frequency distributions, t-tests, and chi-squares.

This study finds that OTs and PTs have differences in perceptions on interprofessional issues that may be generalized to other OTs and PTs. Both disciplines disagree upon attributes that either characterize their own profession or the other profession. It is recommended OTs and PTs acknowledge these barriers and work together in a collaborative manner to overcome them. 


\section{TABLE OF CONTENTS}

CHAPTER

PAGE

I.

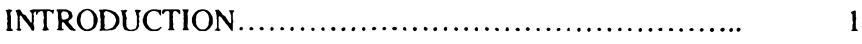

Statement of the Problem.................................. 1

Purpose of the Study...................................... $\quad 2$

Significance of the Study ............................... 2

Research Questions................................... 3

Hypothesis.......................................... 3

Definitions............................................ 4

Assumptions........................................ 6

II. $\quad$ LITERATURE REVIEW ............................. 7

Theoretical Basis and Model: Interdisciplinarity and the Biopsychosocial Model...................................... 7

The Roles of Occupational Therapy and Physical Therapy... 11

Differences in Occupational Therapy and Physical Therapy. 13

Interprofessional Role Relations, .......................... 14

Stereotypes Between Occupational and Physical Therapy

Disciplines........................................... 15

Resolving Conflict................................... 17

Interdisciplinary Collaboration and Leadership............. 17

Summary of Literature Review.......................... $\quad 18$

III. RESEARCH PROCEDURES AND METHODOLOGY ...... 20

Research Questions................................... 20

Hypothesis....................................... $\quad 20$

Subjects...........................................

Research Design ..................................... 22

Instrument............................................. 23

Data Collection.......................................... 25

Statistical Analysis ................................... $\quad 25$

Limitations......................................... 26

$\begin{array}{ll}\text { IV. } & \text { RESULTS }\end{array}$

Characteristics of the Respondents...................... 27

Most Serious Problem Facing Effective Interdisciplinary

Team Functioning........................................ 32

Lack of Effective Interdisciplinary Team Functioning in the Past 10 Years............................................ 35

Educational Methods Influential in Addressing Problems

Between Professions.................................... $\quad 36$

True and False Response Items on the IPS Regarding Own Profession..................................................... 
True and False Response Items on the IPS Regarding the Other Profession........................................... 43

Frequencies of General Comments......................... 46

Independent Sample T-Tests.............................. 46

Question One: Difference in View of Other Profession on Interprofessional Issues................................... 49

Question Two: Difference in View of Other Profession on Practice Issues..............................................

Question Three: Differences in View of OT on Interprofessional Issues......................................

Question Four: Differences in View of OT on Practice Issues

Question Five: Differences in View of PT on Interprofessional Issues....................................
Question Six: Differences in View of PT on Practice Issues Reliability of the IPS Scale.

V. DISCUSSION 53

Significant Results for Research Questions................ 53

Understanding the Capabilities of Each Profession........... 54

Trusting Professional Judgment............................ 54

Status Differences.................................... $\quad 55$

Encroachment on Professional Territory .................. 55

Professional Training.................................. 56

Most Serious Problem Facing Effective Team Functioning $\quad 56$

Educational Methods Influential in Addressing Problems 57

Between Professions.

Encouraging Results.................................... 57

Recommendations for Future Research................... 58

Summary ............................................ 60

LIST OF REFERENCES........................................ 61

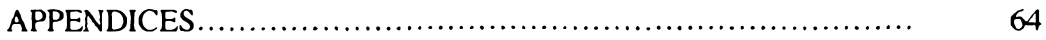




\section{LIST OF TABLES}

TABLE

PAGE

1. Frequencies of Age, Gender, Years of Experience and Degree Earned by Present Profession

2. Frequencies of Specialty Area by Present Profession

3. Frequency of Interdisciplinary Team Membership by Present Profession

4. Frequencies of "Other" Responses for Most Serious Problem Facing Effective Interdisciplinary Team Functioning

5. Frequencies of Responses for Most Serious Problem Facing Effective Interdisciplinary Team Functioning

6. Frequencies of Responses for a Lack of Effective Interdisciplinary Team Functioning in the Past Ten Years

7. Frequencies of Educational Methods Most Influential in Addressing

Problems Between Professions

8. Frequencies of Educational Methods Second Most Influential in

Addressing Problems Between Professions

9. Frequencies of Educational Methods Third Most Influential in Addressing

Problems Between Professions

10. Frequencies of True and False Responses by OTs Regarding Their Own Profession

11. Frequencies of True and False Responses by PTs Regarding Their Own Profession

12. Frequencies of True and False Responses by OTs Regarding the PT Profession

13. Frequencies of True and False Responses by PTs Regarding the OT Profession

14. Mean and Standard Deviations for Interprofessional Issues and Practice Issues of OTs and PTs Regarding Research Questions 
15. Percent of Favorable Responses to Items on the Adapted Portion of the IPS

16. Results of Coefficient Alpha Among IPS Items 


\section{Chapter I}

\section{Introduction}

Occupational therapists (OTs) are often called upon to work as members of interdisciplinary treatment teams in a variety of health and school related settings. Many of these teams consist of individuals with various clinical and professional backgrounds. This study will focus on the specific disciplines of occupational therapy (OT) and physical therapy (PT) working together. Some of these individuals have some commonalties, as well as identifiable differences. Commonalties include: providing appropriate high quality care and service to clients, sharing a similar knowledge base, well established working relationships with other health care professionals, similar work settings and diagnostic groups, as well as therapeutic approaches (Brown and Greenwood, 1998). Differences include: distinctions in some specific course work, an emphasis on psychological diagnostic groups with OT, the use of functional activity related to occupational performance among OTs, and different philosophical backgrounds within each (Brown and Greenwood, 1998, Foto, 1998). It is a wonder how individuals diverse in many ways can work effectively together. Could it be the one universal goal of improving the client's functioning? If this is the case, why don't all therapists learn the same trade, practice the same principles, and serve the same purpose? Although this is an area being studied, this information should be presented to the reader in order for one to better understand the need for this study.

\section{Statement of the Problem}

As mentioned above there is the universal goal of helping the client to improve. Keeping this in mind, OTs and physical therapists (PTs) work side by side to achieve this 
with their clients. Some of these relationships work harmoniously while others do not. There are many factors that can produce barriers that may create conflict between disciplines and interfere with the accomplishment of client related goals (Smith and Lay, 1991). Rothberg (1981) noted that these barriers stem from three overlapping sources: interpersonal, interprofessional, and practice issues. In this investigation, the focus is on interprofessional and practice issues.

If occupational therapists and physical therapists are to function effectively as members of an interdisciplinary team, it is necessary to identify barriers that may create conflict between them. Occupational therapists and physical therapists need to have a clear understanding of their own professional identities. They should clarify how they view their own professions and be aware of how they are perceived by members of other professions. With both OT and PT sharing many commonalties, there is the potential for conflict and misunderstanding between therapists in the two disciplines.

\section{Purpose of the Study}

The purpose of this study was to examine interprofessional perceptions of OT and PT practitioners. Specifically, the goal was to compare interprofessional perceptions that might serve as barriers to effective interdisciplinary team cooperation.

\section{Significance of the Study}

If OT practitioners are to function as members of an interdisciplinary team effectively, it is important to be aware of the barriers that may create conflict between disciplines and thus interfere with improving the client's functional status. It is important to know how OTs view other professions as well as how OTs are viewed. Perhaps if two disciplines can identify a problem in a given area (i.e. competence, autonomy, and 
encroachment), problem solving can be implemented. This is important to the field because it is being faced with many challenging and controversial issues dealing with encroachment (performing outside of one's discipline oriented boundaries). Territorial issues are often seen but there is little or no information as to why they occur. This study helped to identify some of the sources of these issues. In doing so, this study serves as a stepping stone between the two professions for the enhancement of mutual understanding and cooperation.

\section{$\underline{\text { Research Questions }}$}

1. Is there a difference between how OT and PT practitioners view the other profession on interprofessional issues? If so, what specific areas present the greatest disparity?

2. Is there a difference between how OT and PT practitioners view the other profession on practice issues? If so, what specific areas present the greatest disparity?

3. Is there a difference between how OT and PT practitioners view OT on interprofessional issues? If so, what specific areas present the greatest disparity?

4. Is there a difference between how OT and PT practitioners view OT on practice issues? If so, what specific areas present the greatest disparity?

5. Is there a difference between how OT and PT practitioners view PT on interprofessional issues? If so, what specific areas present the greatest disparity? 
6. Is there a difference between how OT and PT practitioners view PT on practice issues? If so, what specific areas present the greatest disparity?

\section{Hypothesis}

1. OT and PT practitioners will differ on how they view the other profession on interprofessional issues.

2. OT and PT practitioners will differ on how they view the other profession on practice issues.

3. OT and PT practitioners will differ on how they view OT on interprofessional issues.

4. OT and PT practitioners will differ on how they view OT on practice issues.

5. OT and PT practitioners will differ on how they view PT on interprofessional issues.

6. OT and PT practitioners will differ on how they view PT on practice issues.

\section{Definitions}

Interdisciplinary team: the involvement or overlapping of two or more health care professions in a collaborative manner (Thomas, 1997).

Occupational therapy: therapeutic use of work, self-care, and play activities to increase independent function, enhance development, and prevent disability: It may include adaptation of tasks or environment to achieve maximum independence and to enhance quality of life (Thomas, 1997); the therapeutic use of purposeful and meaningful occupations (goal-directed activities) to evaluate and treat individuals who have a disease or disorder, impairment, activity limitation, or participation restriction which interferes with their ability to function independently in daily life roles, and to promote health and wellness (AOTA, 1999). 
Physical therapy: the appropriate use of therapeutic exercises, rehabilitative programs, and physical agents such as massage, heat, hydrotherapy, radiation, and electricity, under the direction of a licensed physical therapist (Thomas, 1997); provision of therapeutic exercise, cardiovascular endurance training, and training in activities of daily living (APTA, 1999).

Occupational therapist: one who provides assessment and intervention to ameliorate physical and psychological deficits that interfere with the performance of activities and tasks of daily living (Thomas, 1997); an individual certified, licensed or regulated by a state, district, commonwealth, or territory of the United States to practice as an occupational therapist (AOTA, 1997).

Physical therapist: an individual responsible for evaluating, planning, conducting and supervising a physical therapy program using rehabilitative and therapeutic exercise techniques and physical modalities (Thomas, 1997); an individual responsible for evaluating and treating people with health problems resulting from injury or disease through the assessment of joint motion, muscle strength, endurance, heart and lung functions, and performance of activities of daily living educated at the university level and required to be licensed in the state in which he or she conducts physical therapy practice (APTA, 1999).

Interprofessional issues: attributes that are characteristic of a profession and not unique to a specific work environment (Rothberg, 1981), which may include: competence, understanding capabilities, concern for clients, ethics, status, trusting professional judgment, and training. 
Practice issues: role related attributes that are characteristic of a profession and may vary from one work environment to another (Rothberg, 1981), which may include: autonomy, encroachment on professional territory, work expectations, defensiveness, asking for advice, utilizing professional capabilities, cooperation, and relations with others.

\section{Assumptions:}

The study will be based on the following assumptions:

1. Interprofessional perceptions of the profession different from that of the subjects responding are relatively stable and do not easily fluctuate by situations and circumstances.

2. Interprofessional perceptions of the same profession of the subjects responding are relatively stable and do not easily fluctuate by situations and circumstances.

3. Subjects respond honestly. 


\section{Chapter II}

\section{Literature Review}

Occupational therapists and physical therapists are professionals that work closely together. Cooperation and teamwork are needed to provide optimal patient care. In today's health care arena, OT's and PT's frequently work in shared spaces and occasionally will co-treat the same client. In order to provide the best and most effective treatment for the client, both professions need to work together in coordinating treatment goals and activities. The development of smooth interactive clinical relationships is needed and these relationships may be affected by interprofessional perceptions that arise. These perceptions, attitudes and stereotypes may be either positive or negative and therefore it is important to look at present views of each profession for the other. Further, it may follow that the presence of certain types of views in the clinical situation could influence client care behaviors. Social psychology suggests that beliefs about groups may influence actions toward individuals and that a group's social identity can have implications for intergroup behaviors (Streed and Stoecker, 1991).

\section{Theoretical Basis and Model: Interdisciplinarity and the Biopsychosocial Model}

Interdisciplinarity (Klein, 1990) is a theoretical concept of wide appeal. It is not a new idea but rooted in the ideas of historical figures including Plato, Aristotle, Rabelais, Kant, and others known as the "interdisciplinary thinkers." However, the actual term did not emerge until the twentieth century.

An emergence of this concept has concentrated on the universal idea of unity and synthesis. A range of objectives has been the focus of interdisciplinary work amongst all professionals. These objectives include: 
1. To answer complex questions

2. To address broad issues

3. To explore disciplinary and professional relations

4. To solve problems that are beyond the scope of any one discipline

5. To achieve unity of knowledge, whether on a limited or grand scale

The term interdisciplinarity has brought about much controversy and wide confusion. There are several reasons for this confusion. First, there is an uncertainty about the definition of the term. It has been associated as a historical quest for knowledge by some, while others view it as a developing frontier for new knowledge. Many fields were pronounced interdisciplinary with no clear definition of what that meant. (Klein, 1990)

A second reason for confusion on the meaning and context of the area of interdisciplinarity is the relatively small group of individuals that uses published works or perform research on this subject. Klein (1990) feels this may be the reluctance of placing individual activities into a larger conceptual framework.

A third and final reason for confusion is a lack of a unified body of discourse. Interdisciplinarity is not simply related to the health care industry but spans across other professional, academic, governmental, and industrial literature (Klein, 1990)

Despite areas of ambiguity, interdisciplinarity has continued to evolve in four major ways. According to Klein (1990) these include:

1. Attempts to retain and, in many cases, reinstall historical ideas of unity and synthesis

2. The emergence of organized programs in research and education 
3. The broadening of traditional disciplines

4. The emergence of identifiable interdisciplinary movements.

Interdisciplinarity, as mentioned above, addresses many broad areas with health care being among them. In order for the reader to understand this concept in relevance to this study, it is important to focus on interdisciplinary care in the health care arena. The biopsychosocial model attempts to utilize the concept of interdisciplinarity at a theoretical level.

At a theoretical level, interdisciplinary care is linked with the biopsychosocial model. This is a scientific model that attempts to incorporate missing dimensions of the more hierarchical "biomedical model" with a comprehensive integrative, flexible approach (Engel, 1980). The biopsychosocial model is based on a systems approach. This model incorporates psychological, social, and ethical factors. This concept has brought the term holistic to the health care arena. It also focuses on treating the whole client, which is an underlying concept of integrated health care. Integrated teamwork, which lies at the core of interdisciplinary health care, is holistic in three respects. First, the human being is considered an interacting, integrated whole, and correspondingly, treatment must be dynamic and fluid to keep pace with changes in clients and their needs. Finally, the health care team itself constitutes an interacting partnership of professionals who treat the client as a whole (Whitehouse, 1951).

Hubbard (1991), suggests that one leading factor to the crisis in occupational therapy and its role conflict is dated to the development of the biomedical model in health care. The biomedical model treats disease as a pathology that occurs within the person. The doctor's function is to control the pathology, repair the body and restore health. The 
limitation of this model is that it excludes any psychological, social or ecological factors (Tamm, 1993). Prior to this development, moral treatment was utilized as a means to rehabilitate and restore individuals. Once the biomedical model was in place, a different view of therapeutic intervention from holism to reductionism took place. Kielhofner (1989) proposed that occupational therapy return to behavioral traditions based on moral treatment. However, one must consider that the biomedical model should not be ignored as it has been of great value in the evolution of health care. Once again, Engel's biopsychosocial model does not ignore the biomedical model but combines it with a systems approach. He attempts to explain the relationship between the biological, psychological and sociological facets of human beings and their interaction in the processes of illness, disease and dysfunction (Engel, 1980).

“Engel's model provides an excellent frame of reference for occupational therapy for it bridges the gap between reductionism of medicine and the more global thinking of occupational therapy. This provides a clear means of understanding all treatments, both medical and occupational, and their effects on the whole person: true holism." (Hubbard, 1991, p. 416) This is another reason occupational therapists should turn to the biopsychosocial model for the opportunity to relate to other professions that practice in a reductionistic frame of reference. The biopsychosocial model provides a better opportunity for communication and a true interdisciplinary approach then attempting to separate the two.

Good interdisciplinary care depends on good teamwork (Klein, 1990). An interdisciplinary health care team is a collaborative unit that uses a client or task centered 
approach (Ducanis and Golin, 1979). The effectiveness of any given team is to a large extent a function of the individuals comprising its membership.

Interdisciplinary teamwork has several advantages. It facilitates greater accuracy in assessment, classification, placement, and communication, thereby encouraging modesty and reducing arbitrariness (Koepp-Baker, 1979). It also encourages timely referrals, while providing specialized consultative services and offering resources for developing innovative programs and evaluating existing ones. There are several positive byproducts of teamwork, including the generation of useful databases, rational treatment plans for the future, and increased patient/client advocacy (Morris, 1980).

There are also a number of common problems of teamwork. Individuals do not always have sufficient time for collaborative work, and most of them lack training in group dynamics. There are also problems with overlapping roles, territorial and status conflicts, increased time demands, and unsystematic data collection and analysis. There can be a tendency for certain disciplines to dominate the process, and the entire effort may be plagued by insufficient funding and inadequate logistics (Klein, 1990).

\section{The Roles of Occupational and Physical Therapy}

Although no one definition of occupational and physical therapy may be the same, it is helpful to be able to identify professional identity in order to avoid duplication of services and to provide effective treatment within the domain of each profession. National organizations such as the American Occupational Therapy Association (AOTA) and the American Physical Therapy Association (APTA) have proposed standards.

The following is the definition of OT practice for the AOTA Model Practice Act. "The practice of occupational therapy means the therapeutic use of purposeful and meaningful occupations (goal-directed 
activities) to evaluate and treat individuals who have a disease or disorder, impairment, activity limitation, or participation restriction which interferes with their ability to function independently in daily life roles, and to promote health and wellness. Occupational therapy intervention may include: (1) remediation or restoration of performance abilities that are limited due to impairment in biological, physiological, psychological or neurological processes. (2) adaptation of task, process or the environment, or the teaching of compensatory techniques, in order to enhance performance. (3) disability prevention methods and techniques which facilitate the development or safe application of performance skills. (4) health promotion strategies and practices which enhance performance abilities. Occupational therapy services include, but are not limited to: (1) evaluating, developing, improving, sustaining or restoring skills in activities of daily living (ADLs), work or productive activities, including instrumental activities of daily living (IADLs), and play and leisure activities. (2) evaluating, developing, remediating, or restoring sensorimotor, cognitive, or psychosocial components of performance. (3) designing, fabricating, applying, or training in the use of assistive technology or orthotic devices, and training in the use of prosthetic devices. (4) adaptation of environments and processes, including the application of ergonomic principles, to enhance performance and safety in daily life roles. (5) application of physical agent modalities as an adjunct to or in preparation for engagement in occupations. (6) evaluating and providing intervention in collaboration with the client, family, caregiver, or others. (7) educating the client, family, caregiver, or others in carrying out appropriate nonskilled interventions. (8) consulting with groups, programs, organizations, or communities to provide population-based services." (AOTA, 1999, p. 1)

"Physical therapy, which is the care and services provided by or under the direction and supervision of a physical therapist includes: (1) Examining (history, systems review, and tests and measures) individuals with impairment, functional limitation and disability or other health related conditions in order to determine a diagnosis, prognosis, and intervention; tests and measures may include the following: aerobic capacity and endurance; anthropometic characteristics; arousal, mentation, and cognition; assistive and adaptive devices; community and work (job/school/play) integration and reintegration; cranial nerve integrity; environmental, home, and work (job/school/play) barriers; ergonomics and body mechanics; gait, locomotion, and balance; integumentary integrity; joint integrity and mobility; motor function; muscle performance; neuromotor development and sensory integration; orthotic, protective, and supportive devices; pain; posture; prosthetic requirements; range of motion; reflex integrity; self-care and home management; sensory integrity; and ventilation, respiration, and circulation; (2) Alleviating 
impairment and functional limitation by designing, implementing and modifying therapeutic interventions that may include, but are not limited to: coordination, communication, and documentation; patient/clientrelated instruction; therapeutic exercises (including aerobic conditioning); functional training in self-care and home management (including activities of daily living and instrumental activities of daily living); functional training in community and work (job/school/play) integration or reintegration activities (including instrumental activities of daily living, work hardening, and work conditioning); prescription, application, and, as appropriate, fabrication of assistive, adaptive, orthotic, protective, supportive, and prosthetic devices and equipment; airway clearance techniques; wound management; electrotherapeutic modalities; and physical agents and mechanical modalities; (3) Preventing injury, impairment, functional limitation, and disability, including the promotion and maintenance of fitness, health, and quality of life in all age populations; and (4) engaging in consultation, education and research." (APTA, 1999, p. 2)

\section{Differences in Occupational and Physical Therapy}

According to Foto (1998), there are major differences between the two discipline's philosophies, mission, treatment focus, and outcome expectations. While physical therapy has recently included functional abilities in daily living skills, including in its scope of practice such areas as work, physical therapy's focus in this area remains different from that of occupational therapy. Physical therapy approaches daily living skills from the perspective of the body and its function in the immediate present. Occupational therapy, on the other hand, approaches daily living skills from a purposeful activities perspective that addresses the person's function in his or her community over the life span. Golledge (1998) agrees with these distinctions in the professional therapeutic media. He also makes reference to Yerxa. Yerxa stated, "Health professionals need to have a good understanding of their own identity if they are to practice confidently with each other. Cooperative practice isn't achieved by trying to be another professional" (Yerxa, 1995, p. 295). This statement provides the insight for 
acknowledging the need for identification of interprofessional perceptions between both professions. A better understanding of each other can only result in an increase in the amount of confident practice taking place.

\section{Interprofessional Role Relations}

Professionals working together in a multi-professional team often experience problems in establishing and sustaining interprofessional collaboration. Peck and Norman (1999) suggest these problems are mainly related to differences in culture between professional groups and to the different values held by group members. These differences originate in professional training and are maintained subsequently by socialization. The procedure through which interprofessional perceptions will be explored may provide a valuable approach to identifying interprofessional conflict and promoting understanding of professional roles.

Another study conducted by Strasser, Falconer, and Martino-Saltzmann (1994) addressed interprofessional relations. This study surveyed 113 staff from selected inpatient teams in an inpatient rehabilitation hospital setting. The staff completed social psychological instruments that measured perceptions of the hospital environment (The Ward Atmosphere Scale [WAS]), the team's environment (the Group Environment Scale [GES]), and interprofessional relations (Interprofessional Perception Scale [IPS]). Their findings suggested that rehabilitation staff generally endorsed the team approach, but expressed concerns over professional boundaries. Interprofessional difficulties seemed to be independent of team membership or professional training. Compared with published data from other settings, rehabilitation teams resembled task-oriented groups, but showed significant differences across teams in their perceptions of the team and hospital 
environments. The task-oriented character of rehabilitation teams, team specific characteristics, and discord in interprofessional relationships may need to be considered in studies in rehabilitation teams effectiveness.

After reviewing these and other such articles on interprofessional role relations, the researcher feels the IPS could also prove useful in looking at individual professions, such as occupational therapy and physical therapy.

\section{Stereotypes Between Occupational and Physical Therapy Disciplines}

Stereotyping can be defined as "a belief or idea about the characteristics of a group or people, held in common by a separate group (Streed and Stoecker, 1991, p. 16)". The formation of stereotypes begins with a lack of information about a group. The fewer people available from within a group to help form an impression, the more likely a group will be judged on the basis of an individual's characteristics. Simplification and categorization magnify intergroup differences but may also understate intragroup differences (Hewstone, Stroebe, Codol, and Stephen, 1988).

Four articles have been published that assess the perceptions of occupational and physical therapists toward each other utilizing stereotypes. Parker and Chan (1986a, 1986b) published two studies in which physical and occupational therapists were asked to reflect on their own and each other's discipline for the purpose of detecting evidence of stereotyping behavior. One of the studies utilized the Allied Health Professions Rating Scale, which defined prestige as the esteem or level of social standing attributed to an occupation. Results found that both physical and occupational therapists ranked PTs first among 13 allied health professions. OTs were ranked fourth by themselves and fifth by 
physical therapists. Parker and Chan concluded that OTs did not perceive their professional status to be as high as that of physical therapists (Parker and Chan, 1986a).

The second study conducted by Parker and Chan (1986b) focused specifically on the stereotypes that might exist between PT and OT. The Health Team Stereotype Scale (HTSS) was used to determine the extent of differences between the two professions. Findings suggest the PTs viewed themselves more positively than the OTs viewed the PTs. The OTs view of themselves was congruent with views of the PTs toward the OTs. Parker and Chan concluded that the self-perceptions of physical therapists did not statistically differ from the self-perceptions of occupational therapists.

A third article focused on the perceptions of physical and occupational therapy students toward each other. A Midwestern university was utilized to obtain subjects for the study. The HTSS was used. The results of this study demonstrated that physical therapy students' self-perceptions were not significantly different from occupational therapy students' self-perceptions. This study also showed that the individual disciplines viewed themselves more positively than they viewed the other discipline (Streed, and Stoecker, 1991).

The fourth study (Kamps, Page, Seagrave, Sweet, Zettergren, \& MacKinnon, 1996), which was similar to the third study, elaborated on the geographic location and number of participants. This study surveyed 687 students from 28 programs. Findings were similar to Streed and Stoecker's work where PT and OT students viewed themselves more positively than the other discipline.

Based upon these findings, the research suggests the need for increasing the awareness of the views of both OT and PT professionals and students. 


\section{$\underline{\text { Resolving Conflict }}$}

According to Liston and Docking (1985), conflict should be resolved in the following manner. First, exact definitions should be made to highlight the exact meaning of the tasks and the precise differences between the professions. If this step doesn't resolve the conflict, then it is proposed that the conflict be arbitrated by a Review Panel comprised of an independent chairperson and one representative of each profession. Liston and Docking (1985) also note that the responsibility for successful interprofessional liaison lies personally with each therapist. In order to maintain the highest ethical principles in the pursuit of their profession, OTs and PTs need to communicate honestly with each other and other members of the health care team. Interdisciplinary Collaboration and Leadership

An area currently being focused on in the provision of education for health care service providers is interdisciplinary collaboration. Collaboration among medical disciplines enables practitioners to provide optimal health care to clients. In particular, two studies have focused on the interdisciplinary collaboration in academic education.

One such study by Tryssenaar, Perkins, and Brett (1996) presented information regarding interdisciplinary education involving undergraduate physical therapy and occupational therapy programs in Canada. This paper states interdisciplinary practice is encouraged and even mandated in many health care settings. However, they note interdisciplinary teams do not live up to their full potential. Questions were asked about current activities, anticipated changes and the level of formal institutional support for interdisciplinary education. Their results indicated that interdisciplinary activities are encouraged now and many programs hope to expand in the future. 
In addition, MacKinnon and MacRae (1996) created a structured academic experience for the medical, occupational and physical therapy students at the University of New England in which the students worked together using a geriatric case study format. Students who participated in the experience reported it to be beneficial. In addition, data collected during the experience confirmed previous research findings that these disciplines use a common clinical reasoning process to generate clinical hypotheses. These results would support the continuation of such academic experiences for the purpose of fostering geriatric interdisciplinary collaboration, particularly between occupational and physical therapists.

As health care service providers, both OTs and PTs will be called upon to provide leadership in the health care arena. It is important to be aware of the interprofessional perceptions of each other. Furthermore, according to Abreu (1997), interdisciplinary leadership is a collaborative process that assesses, plans, implements, coordinates, monitors, and evaluates the options and services required to influence all members of a group and meet its established goals. Without knowledge of the interprofessional perceptions of each discipline, one cannot assume OTs or PTs can take on such a leadership role and be effective for all members of a group.

\section{Summary of Literature Review}

Perhaps the findings presented in the literature review helped the reader relate to the need for a study to address an understanding of each discipline's perceptions of the professions. Ultimately, there is a need to provide the best client care possible.

Reviewing the findings in the publications above in more detail may help in formulating 
potential pathways clinicians can take in order to provide the best client care and work effectively with other disciplines. 


\section{Chapter III}

\section{Research Procedures and Methodology}

This study explored the interprofessional perceptions OTs and PTs have on interprofessional issues and practice issues within their own profession and in each other's profession. The following research questions and hypothesis were addressed:

\section{Research Questions}

1. Is there a difference between how OT and PT practitioners view the other profession on interprofessional issues? If so, what specific areas present the greatest disparity?

2. Is there a difference between how OT and PT practitioners view the other profession on practice issues? If so, what specific areas present the greatest disparity?

3. Is there a difference between how OT and PT practitioners view OT on interprofessional issues? If so, what specific areas present the greatest disparity?

4. Is there a difference between how OT and PT practitioners view OT on practice issues? If so, what specific areas present the greatest disparity?

5. Is there a difference between how OT and PT practitioners view PT on interprofessional issues? If so, what specific areas present the greatest disparity?

6. Is there a difference between how OT and PT practitioners view PT on practice issues? If so, what specific areas present the greatest disparity?

\section{Hypothesis}

1. OT and PT practitioners will differ on how they view the other profession on interprofessional issues. 
2. OT and PT practitioners will differ on how they view the other profession on practice issues.

3. OT and PT practitioners will differ on how they view OT on interprofessional issues.

4. OT and PT practitioners will differ on how they view OT on practice issues.

5. OT and PT practitioners will differ on how they view PT on interprofessional issues.

6. OT and PT practitioners will differ on how they view PT on practice issues.

\section{$\underline{\text { Subjects }}$}

Target populations were OTs and PTs employed in the United States. Variables considered on the survey included: age, gender, field of practice, practice setting, years of practice, and highest degree earned. Data on these variables were obtained from a list of OTs and PTs who were members of national organizations, and by successful completion of a demographic section on the questionnaire. National organizations utilized for this study were AOTA and APTA. Sampling selection design for the subjects was a probability type sample. A simple random sample to select which individuals were sent a survey was drawn from list directories compiled by each national organization. A random number device to select individuals from a list was selected to pick therapists from each professional organization. A total of 400 surveys were sent to those in the sample, along with a cover letter. The cover letter stated the purpose of the study and asked that the questionnaire be returned by October 15, 2001 (Appendix). Mailing labels consisting of occupational therapists were printed, purchased, and obtained from AOTA. AOTA provided a total of 500 pressure sensitive labels of 
randomly selected OTs in the United States. This list was compiled on 8/13/01 from a total list of occupational therapists registered (OTR) estimating 37, 298 individuals as of 9/00. The researcher randomly selected 200 OTs from this list to conduct the mailing.

A list of physical therapists was obtained online from the Directory of Certified Clinical Specialists in Physical Therapy compiled by APTA in 2000. This directory included a listing of 2,806 certified individuals who have demonstrated advanced clinical knowledge and skills in physical therapy specialty areas. These specialty areas included: cardiopulmonary, clinical electrophysiologic, geriatric, neurologic, orthopedic, pediatric, and sports physical therapy. The primary investigator randomly selected 200 PTs on $8 / 12 / 01$ from this list to conduct the mailing. Due to significant financial costs involved in obtaining equivalent mailing labels from APTA's PT registrar, the online directory was used to provide such a list. This may have suggested a bias to the survey with PTs being certified in a specialized area.

\section{$\underline{\text { Research Design }}$}

A survey type research method was used to compare interprofessional perceptions that might serve as barriers to effective interdisciplinary team functioning (Appendix). It consisted of three parts. First, a general demographic information section that included the following information: age, gender, field of practice, practice setting, years of practice, and highest degree earned. Four questions were also asked regarding membership of an interdisciplinary team, most serious problems facing the professions, changes in effective team functioning in the past ten years, and potential influential educational methods that may be implemented to address problems between OTs and 
PTs. Participants were encouraged to complete all questions. A total of 10 questions composed part 1 of the survey.

The second part provided an adapted portion of the Interprofessional Perception Scale (IPS). Individuals participating in the survey were asked to answer the following items and not to spend too much time on any one statement. First impressions were desired. Individuals were asked to answer with as much candor as possible and to answer each item. This portion consisted of two sections. Each section was estimated to take 2-3 minutes. The first section addressed how an individual viewed his/her own profession. It consisted of 15 statements. These statements were answered in a true or false format. The second section addressed how an individual viewed the profession that was not his/her own profession. It consisted of 15 statements to be answered in a true or false format. Both sections were written in a user friendly format identifying occupation specific terminology to decrease confusion and to promote increased speed while answering the statements. A total of 30 statements composed part 2 of the survey.

A final section allowed for open-ended comments so that the therapist provided feedback regarding any important issues which may have been omitted and for general comments to help the examiner for future use. The third part of the survey was optional.

The surveys were mailed out and coded such that individuals who responded would not be included if a second mailing became necessary. To ensure the anonymity of each respondent's participation, all data were treated as group data.

\section{Instrument}

The instrument for this study utilized in Part 2 was an adapted portion of the Interprofessional Perception Scale (IPS) developed by Ducanis and Golin (1979). This 
two-version scale, based upon the work of Laing, Phillipson, and Lee (1966), examined any pair of professions on three levels of interprofessional perception. These three levels of interprofessional perceptions address the following.

“...asks a professional to give an opinion of another profession (Level I), tell how members of that profession would respond (Level II), and tell how those professional would say he or she responded (Level III). Thus, the IPS yields data regarding how a professional views another profession, whether he or she thinks that members of that profession agree or disagree with that view, and whether they understand that perception. The scale can also be used to indicate how subjects see their own profession and whether they think other professionals agree with or understand this perception." (Ducanis and Golin, 1979)

For this study, the scales were modified, with permission by the author, to meet the examiner's objectives with Level I responses utilized to address statements of an individual's profession that was his or her own and not his/her own. For each of the 15 items on Section I of the IPS, it determined the respondent's view of his or her own profession. Section II of the scale was similar to the first. However, it determined the respondent's perceptions of the profession other than his or her own profession. Both sections of the scale used a true-false response format. Ducanis and Golin (1979) reported a mean reliability coefficient of .80 for Level I responses with content validity maintaining that the items directly represented the concept of interprofessional perception.

The 15 true-false statements were divided into interprofessional issues and practice issues by Smith, Perry, Neumayer, Potter, and Smeal (1992) based upon definitions provided in the literature. Seven items were categorized as interprofessional issues. These related to competence, understanding capabilities, concern for clients, ethics, status, trusting professional judgment, and training. Eight items were categorized 
as practice issues. These related to autonomy, encroachment on professional territory, work expectations, defensiveness, asking for advice, utilizing professional capabilities, cooperation, and relations with others (Appendix).

\section{Data Collection}

A pilot survey was given to 15 occupational therapists and 10 physical therapists working in Dade County, FL. Responses and feedback obtained from the pilot testing were used to modify, clarify and refine the questionnaire. The researcher and the thesis chair modified the final questionnaire based on information obtained from the pilot study.

Basic demographic data were obtained. Specifically, information on age, gender, field of practice, practice setting, years of practice, and highest degree earned was focused on. The second section completed was the adapted portion of the Interprofessional Perception Scale (IPS). A final optional section for open-ended comments was completed so that the therapist could provide feedback regarding any important issues which may have been omitted and for general comments to help the examiners for future use.

\section{Statistical Analyses}

Because of the qualitative nature of the survey design, descriptive statistics and frequency distributions were utilized to provide data. Specific statistical tests included independent sample t-tests, co-efficient alpha reliabilities, and chi-squares.

Specific computer analysis of the data was obtained through the use of the Statistical Package for the Social Sciences (SPSS) Version 10.0. SPSS was chosen secondarily to its power and flexibility as a data analysis package. 


\section{Limitations}

Generalization of the results of this study to OTs and PTs was limited for the following reasons:

1. The random mailing list that was generated may not be representative of the population of all OT's and PT's.

2. The random mailing list produced for the PTs may suggest bias due to the list being generated from a directory of specialists.

3. The return rate may have suggested a self-selection bias.

4. The researcher was assuming the respondents have answered the questions truthfully and accurately. 


\section{Chapter IV}

\section{$\underline{\text { Results }}$}

\section{Characteristics of the Respondents}

Of the 400 questionnaires that were mailed, 26 PT questionnaires were returned to sender so 374 were received. Of the 374 questionnaires, 217 therapists responded for an overall return rate of $58 \%$. Two hundred questionnaires were sent to OTs. The questionnaires returned from OTs totaled $128(64 \%)$. Of the 128 questionnaires returned, $106(82 \%)$ were identified as usable for this research. One hundred and seventy four questionnaires were sent to PTs. Eighty-nine PTs (51\%) responded with 76 (85\%) questionnaires identified as usable. A total of $182(49 \%)$ questionnaires were used for data analysis.

OTs reported their age ranging from under 25 years of age to 65 years of age. The majority of OTs (36\%) were 36 through 45 years of age. PTs' ages ranged from under 25 years of age to over 65 years of age. The majority of PTs $(47 \%)$ were between 36 through 45 years of age, as well. A significant difference was seen in age by profession, $X^{2}(5, n=181)=11.21, p<.05$. The majority of PTs were older than OTs. The respondents' ages are summarized in Table 1 .

Gender was identified by all OTs and PTs $(n=182)$. A total of $147(81 \%)$ females and $35(19 \%)$ males completed the survey. Of the females, a total of 102 were OTs and 45 were PTs. Of the males a total of 4 OTs and 31 PTs responded. A significant difference was seen in gender by profession, $X^{2}(1, n=182)=39.05, p<.001$. Ninety six percent of the OT sample was female but only $59 \%$ of PTs were. Table 1 displays the distribution. 
Both professions reported between 0 to over 25 years of experience in their professions. The majority of OTs (29\%) had between 0 and 5 years of experience in their field. The next largest group of OTs $(21 \%)$ had between 6 and 10 years of experience. PTs' largest groups had between 11 and 15 years of experience $(24 \%)$ and over 25 years of experience ( $24 \%$ ). A significant difference was seen in years of experience by profession, $X^{2}(5, n=182)=28.74, p<.001$. The majority of OTs responding had less experience than PTs and this is illustrated in Table 1.

The majority of the OTs (58\%) held bachelor's degrees, while 39\% held master's degrees, and $2 \%$ held doctorate degrees. The PTs had higher levels of education with $46 \%$ having bachelor's degrees, $41 \%$ with master's degrees, and $12 \%$ with doctorate degrees. A significant difference was seen in degree level by profession, $X^{2}(3, n=182)=$ $8.50, \mathrm{p}<.05$. Table 1 represents the respondents' highest degree level. 
Table 1

Frequencies of Age, Gender, Years of Experience and Degree Earned by Present Profession ( $n=182)$

OCCUPATIONAL THERAPISTS

n

Age $^{a}$

25 YEARS AND UNDER

26-35 YEARS

36-45 YEARS

46-55 YEARS

56-65 YEARS

OVER 65 YEARS

Gender

$$
\text { MALE }
$$

FEMALE
10

33

38

19

5

--
$\%$

18.1

4.8

4

3.8

102

96.2

PHYSICAL

THERAPISTS

n

$\%$

\section{6}

18.4

$31.4 \quad 14$

47.4

$36.2 \quad 36$

19

25.0

3.9

3

2.6

2

$\begin{array}{lll}-- & 2 & 2.6\end{array}$

31

40.8

45

59.2

Years of

Experience

$\begin{array}{lcccc}0-5 \text { YEARS } & 31 & 29.2 & 3 & 3.9 \\ \text { 6-10 YEARS } & 22 & 20.8 & 11 & 14.5 \\ 11-15 \text { YEARS } & 14 & 13.2 & 18 & 23.7 \\ 16-20 \text { YEARS } & 19 & 17.9 & 17 & 22.4 \\ \text { 21-25 YEARS } & 13 & 12.3 & 9 & 11.8 \\ \text { MORE THAN 25 YEARS } & 7 & 6.6 & 18 & 23.7\end{array}$

Note. Table 1 is continued on the following page

${ }^{a} \mathrm{n}=181,1$ OT respondent did not indicate age

Age: $X^{2}(5, n=181)=11.21,{ }^{*} p<.05$.

Gender: $\mathrm{X}^{2}(1, \mathrm{n}=182)=39.05, * * * \mathrm{p}<.001$.

Years of Experience: $\mathrm{X}^{2}(5, \mathrm{n}=182)=28.74,{ }^{* * *} \mathrm{p}<.001$. 
Table 1 cont.

Frequencies of Age, Gender. Years of Experience and Degree Earned by Present

Profession $(n=182)$

OCCUPATIONAL

THERAPISTS

n

Degree

Earned
PHYSICAL THERAPISTS

n

$\%$

$\begin{array}{lcccc}\text { BACHELOR } & 61 & 57.5 & 35 & 46.1 \\ \text { MASTER } & 41 & 38.7 & 31 & 40.8 \\ \text { DOCTORATE } & 2 & 1.9 & 9 & 11.8 \\ \text { OTHER } & 2 & 1.9 & 1 & 1.3\end{array}$

Note. Degree Earned: $X^{2}(3, n=182)=8.50,{ }^{*} p<.05$.

Table 2 outlines the specialty areas of the respondents. The majority of the OTs $(n=26,25 \%)$ worked in the school system. The majority of PTs $(n=34,45 \%)$ indicated the "other" category. PT respondents replying "other" indicated the following specialty areas: orthopedic $(n=25)$, cardiopulmonary $(n=2)$, electromyography $(n=2)$, neurology $(n=1)$, oncology $(n=1)$, vestibular rehabilitation $(n=1)$, and certification review management $(n=1)$. No PTs worked in the specialty areas addressed on the questionnaire of mental health, technology, or work programs. No chi-square test was carried out on distribution of specialty area by profession due to small cell sizes. 
Table 2

Frequencies of Specialty Area by Present Profession $(n=182)$

\section{OCCUPATIONAL THERAPISTS}

Specialty Area

School Systems

Pediatrics

Education

Geriatrics

Home and Community Health

Mental Health

Physical Disabilities

Hand Therapy

Technology

Work Programs

Other

$\begin{array}{cccc}\mathrm{n} & \% & \mathrm{n} & \% \\ 26 & 24.5 & 2 & 2.6 \\ 23 & 21.7 & 9 & 11.8 \\ 3 & 2.8 & 11 & 14.5 \\ 17 & 16.0 & 9 & 11.8\end{array}$

4

6

14

8

1

1

3
3.8

2

2.6

5.7

13.2

7.5

.9

.9

2.8
PHYSICAL

THERAPISTS

Note. ${ }^{\text {PPT }}$ respondents replying other indicated orthopedic $(n=25)$, cardiopulmonary $(n=2)$, electromyography $(n=2)$, neurology $(n=1)$, vestibular rehabilitation $(n=1)$, and certification review management $(n=1)$.

Table 3 illustrates 144 respondents were members of an interdisciplinary team.

OTs accounted for 90 individuals with PTs totaling 54. There was a significant difference in percentages of therapists who were part of an interdisciplinary team by profession, $\mathrm{X}^{2}(1, \mathrm{n}=182)=5.14, \mathrm{p}<.05$. 
Table 3

Frequency of Interdisciplinary Team Membership by Present Profession ( $n=182$ )

Member of an Interdisciplinary

Team

YES

90

$\%$

PHYSICAL

OCCUPATIONAL

THERAPISTS

THERAPISTS

NO

16

84.9

$\mathrm{n}$

$\%$

Note. $X^{2}(1, n=182)=5.14,{ }^{*} p<.05$.

54

22

28.9

\section{Most Serious Problem Facing Effective Interdisciplinary Team Functioning}

In response to the question asking the therapists' opinions of the most serious problem facing effective interdisciplinary team functioning amongst OTs and PTs, an overall response of $36 \%$ reflected encroachment problems, with competency (26\%) and ethical problems (9\%) following after. When indicating "other", 49 therapists (26.9\%) provided 19 additional responses. No chi-square test was carried out on distribution of the "other" category due to small cell sizes. Table 4 highlights these responses. More specifically, OTs (43\%) responded that encroachment problems presented the most serious problem as opposed to $42 \%$ of PTs who indicated competency as the most serious problem. A significant difference was seen between these responses, $X^{2}(4, n=180)$ $=22.67, \mathrm{p}<.001$. Please see Table 5 . 
Table 4

Frequencies of "Other" Responses for Most Serious Problem Facing Effective Interdisciplinary Team Functioning $(n=49)$

OCCUPATIONAL

THERAPISTS

"Other" Responses

No problems

Decreased communication

Decreased time

Interpersonal skills

Decreased understanding of other

professional roles

Interdisciplinary respect

Reimbursement issues

Lack of treatment space

Attitudes towards other professions learned in school

Knowing how to work as a cooperative member of a team for the good of a patient

Both professions are thought of at the last minute

Late reports from other therapists

Role delineation

Increased case load size

Truly functioning as an interdisciplinary team

Habits in certain geographic regions

Note. Table 4 is continued on the following page
PHYSICAL

THERAPISTS

n

$\%$

n

$\%$

5

17.9

5

23.8

5

17.9

5

23.8

4

14.3

2

9.5

1

3.6

2

9.5

1

3.6

4.8

2

7.1

1

3.6

4.8

1

3.6

3.6

3.6

3.6

3.6

3.6

3.6

1

-.

--

1

4.8

4.8 
Table 4 cont.

Frequencies of "Other" Responses for Most Serious Problem Facing Effective Interdisciplinary Team Functioning $(n=49)$

OCCUPATIONAL
PHERAPICAL
THERAPISTS

"Other" Responses

$\begin{array}{cccc}\mathrm{n} & \% & \mathrm{n} & \% \\ -- & -. & 1 & 4.8 \\ - & -- & 1 & 4.8 \\ -- & -- & 1 & 4.8 \\ 2 & 7.1 & -. & --\end{array}$

Table 5

Frequencies of Responses for Most Serious Problem Facing Effective Interdisciplinary Team Functioning $\left(n=180^{a}\right)$

Most Serious Problem Facing Effective Interdisciplinary Team Functioning

OCCUPATIONAL THERAPISTS

Encroachment Problems

Competency Problems

Ethical Problems

Other

Note. ${ }^{a} n=180,2$ OTs did not respond $\mathrm{X}^{2}(4, \mathrm{n}=180)=22.67,{ }^{* * *} \mathrm{p}<.001$.

\section{THERAPISTS}

$\mathrm{n}$

45

16

15

28

$\begin{array}{rlcc}\mathrm{n} & \% & \mathrm{n} & \% \\ 45 & 43.3 & 21 & 27.6 \\ 16 & 15.4 & 32 & 42.1 \\ 15 & 14.4 & 2 & 2.6 \\ 28 & 26.9 & 21 & 27.6\end{array}$

PHYSICAL

THERAPISTS

$\%$

27.6

2.1

2.6

27.6 
The majority of OTs (39\%) were not able to respond to the question addressing a lack of interdisciplinary team functioning being more, about the same, or less of a problem than it was 10 years ago due to not being a member of the profession for 10 or more years. About the same (27\%) was the next most frequent response indicated by OTs. The most frequent response (38\%) indicated by PTs stated effective interdisciplinary team functioning in the past ten years was less of a problem. About the same (37\%) was the next most frequent response indicated by PTs. These responses are summarized in Table 6.

Table 6

Frequencies of Responses for a Lack of Effective Interdisciplinary Team Functioning in the Past Ten Years $\left(n=180^{2}\right)$

Effective Interdisciplinary Team

Functioning in the Past Ten Years

More

About the Same

Less

Not Applicable ${ }^{\mathrm{h}}$

Note. ${ }^{a}=180,2$ OTs did not respond

${ }^{b}$ Respondents not applicable if not a member of the profession 10 years or more.
PHYSICAL THERAPISTS

THERAPISTS

n $\quad \% \quad$ n $\quad \%$

13

12.5

12 15.8

28

26.9

28

36.8

23

22.1

29

38.2

40

38.5

7

9.2 


\section{Educational Methods Influential in Addressing Problems Between Professions}

The educational method most influential in addressing problems between OTs and PTs chosen most frequently by OTs $(46 \%)$ and PTs $(51 \%)$ was increasing amount of collaboration during professional training prior to receiving degree/certification/licensure. The second most influential education method chosen was participating in interdisciplinary collaboration of educational fieldwork with $42 \%$ of OTs and $42 \%$ of PTs indicating this response. Attending onsite in-services was selected as the third most influential educational method by both OTs (33\%) and PTs (34\%). No significant differences were seen in educational methods chosen by profession. Please see Tables 7 , 8 , and 9 for a total summation of these results. 
Table 7

Frequencies of Educational Methods Most Influential in Addressing Problems Between Professions $\left(\mathrm{n}=176^{\mathrm{a}}\right)$

OCCUPATIONAL

THERAPISTS
PHYSICAL

THERAPISTS

First Most Influential Educational Methods

n

$\%$

n

$\%$

Attending on site staff in-services

22

21.6

10

13.5

Participating in interdisciplinary

collaboration of educational coursework

27

26.5

17

23.0

Attending seminars/workshops

2

2.0

3

4.1

Practicing simulated exercises during

facility orientation

3

2.9

2

2.7

Increasing knowledge from reading journal and scholarly publications

1

1.0

4

5.4

Increasing amount of collaboration during professional training prior to receiving 47

46.1

38

51.4

Note. ${ }^{a} n=176,4$ OTs and 2 PTs did not respond $\mathrm{X}^{2}(6, \mathrm{n}=176)=5.80, \mathrm{p}<.445$. 


\section{Table 8}

Frequencies of Educational Methods Second Most Influential in Addressing Problems Between Professions $\left(n=176^{\circ}\right)$

Second Most Influential Educational

Methods

OCCUPATIONAL

THERAPISTS

Attending on site staff in-services

Participating in interdisciplinary

collaboration of educational coursework

Attending seminars/workshops

Practicing simulated exercises during

facility orientation

Increasing knowledge from reading journal and scholarly publications

Increasing amount of collaboration during professional training prior to receiving degree/certification/licensure

Note. ${ }^{a} n=176,4$ OTs and 2 PTs did not respond $\mathrm{X}^{2}(6, \mathrm{n}=176)=7.80, \mathrm{p}<.256$.

$-\cdot \quad-\cdot$ n

11

PHYSICAL THERAPISTS

43

42.2

31

10

9.8

9

12.2

11

10.8

7

9.5

4

27

26.5

13

17.6 
Table 9

Frequencies of Educational Methods Third Most Influential in Addressing Problems Between Professions $\left(n=176^{a}\right)$

OCCUPATIONAL
PHERAPICAL
THERTS

Third Most Influential Educational Methods

Attending on site staff in-services

Participating in interdisciplinary

collaboration of educational coursework

Attending seminars/workshops

Practicing simulated exercises during

facility orientation

Increasing knowledge from reading journal and scholarly publications

Increasing amount of collaboration during professional training prior to receiving degree/certification/licensure

Note. ${ }^{a} \mathrm{n}=176,4$ OTs and 2 PTs did not respond $\mathrm{X}^{2}(6, \mathrm{n}=176)=7.00, \mathrm{p}<.321$. n

33

14

17

21

6

5.9

8

10.8

10

9.9

9

12.2 
True and False Response Items on the IPS Regarding Own Profession

Section I on the second part of the survey consisting of the adapted IPS contained 15 items in a true/false format for each profession to answer in regards to his/her own profession. Ninety nine percent of the OTs indicated that OTs were highly concerned with the welfare of the patient. This was followed by $97 \%$ of OTs reporting OTs are competent. The most true responses provided by PTs were for $98 \%$ of PTs stating they were highly concerned with the welfare of the patient and PTs are well trained. The most false responses given by OTs included $98 \%$ of OTs stating false to two statements. First, OTs have a higher status than PTs and OTs do not cooperate well with PTs. Ninety six percent of PTs stated false to the statement, "PTs expect too much of the OT profession". Table 10 and Table 11 represent all responses for Section I. 
Table 10

Frequencies of True and False Responses by OTs Regarding Their Own Profession $(\mathrm{n}=182)$

\section{TRUE FALSE}

\section{SECTION I Statements}

Occupational therapists are competent

Occupational therapists have very little autonomy

Occupational therapists understand the capabilities of physical therapists

Occupational therapists are highly concerned with the welfare of the patient

Occupational therapists sometimes encroach on physical therapy professional territory

Occupational therapists are highly ethical

Occupational therapists expect too much of the physical therapy profession

Occupational therapists have a higher status than physical therapists Occupational therapists are very defensive about their professional prerogatives

Occupational therapists trust physical therapists' judgment

Occupational therapists seldom ask physical therapists' professional advice

Occupational therapists fully utilize the capabilities physical therapists

Occupational therapists do not cooperate well with physical therapists

Occupational therapists are well trained

Occupational therapists have good relations with physical therapists n $\%$ n $\%$

$\begin{array}{llll}103 & 97.2 & 3 & 2.8\end{array}$

$\begin{array}{llll}15 & 14.2 & 9 \mathrm{I} & 85.8\end{array}$

$\begin{array}{llll}98 & 92.5 & 8 & 7.5\end{array}$

$\begin{array}{llll}105 & 99.1 \quad 1 & 9\end{array}$

$\begin{array}{llll}65 & 61.3 & 41 & 38.7\end{array}$

$\begin{array}{llll}101 & 95.3 & 5 & 4.7\end{array}$

$\begin{array}{llll}3 & 2.8 & 103 & 97.2\end{array}$

$\begin{array}{llll}2 & 1.9 & 104 & 98.1\end{array}$

$\begin{array}{llll}48 & 45.3 & 58 & 54.7\end{array}$

$\begin{array}{llll}95 & 89.6 & 11 & 10.4\end{array}$

$\begin{array}{llll}4 & 3.8 & 102 & 96.2\end{array}$

$\begin{array}{llll}71 & 67.0 & 35 & 33.0\end{array}$

$\begin{array}{llll}2 & 1.9 & 104 & 98.1\end{array}$

$\begin{array}{llll}94 & 88.7 & 12 & 11.3\end{array}$

$\begin{array}{llll}98 & 92.5 & 8 & 7.5\end{array}$ 
Table 11

Frequencies of True and False Responses by PTs Regarding Their Own Profession $\underline{(n=182)}$

\section{TRUE FALSE}

\section{SECTION I Statements}

Physical therapists are competent

$\begin{array}{cccc}\text { n } & \% & \text { n } & \% \\ 74 & 97.4 & 2 & 2.6 \\ 7 & 9.2 & 69 & 90.8 \\ 54 & 71.1 & 22 & 28.9\end{array}$

Physical therapists understand the capabilities of occupational therapists

Physical therapists are highly concemed with the welfare of the patient

Physical therapists sometimes encroach on occupational therapy professional territory

Physical therapists are highly ethical

$\begin{array}{llll}72 & 94.7 & 4 & 5.3\end{array}$

Physical therapists expect too much of the occupational therapy profession

Physical therapists have a higher status than occupational therapists

$\begin{array}{llll}34 & 44.7 & 42 & 553\end{array}$

Physical therapists are very defensive about their professional prerogatives

$\begin{array}{llll}31 & 40.8 & 45 & 59.2\end{array}$

Physical therapists trust occupational therapists' judgment

$\begin{array}{llll}65 & 85.6 & 11 & 14.5\end{array}$

Physical therapists seldom ask occupational therapists' professional advice

Physical therapists fully utilize the capabilities of occupational therapists

Physical therapists do not cooperate well with occupational therapists

Physical therapists are well trained

$\begin{array}{llll}75 & 98.7 & 1 & 1.3\end{array}$

Physical therapists have good relations with occupational therapists

$\begin{array}{llll}68 & 89.5 & 8 & 10.5\end{array}$ 
True and False Response Items on the IPS Regarding the Other Profession

Section II on the second part of the survey consisting of the adapted IPS contained 15 items in a true/false format for each profession to answer in regards to the profession that was not his/her own profession. The majority of true responses by OTs (98\%) indicated they felt PTs were well trained. A high true response rate by OTs $(97 \%)$ was also seen stating PTs are competent. All PTs (100\%) felt OTs were highly concerned with the welfare of the patient, with $99 \%$ of true responses indicating OTs are competent. The most false responses given by OTs included $96 \%$ of OTs stating false to two statements. The first statement was PTs have very little autonomy. The second statement was PTs expect too much from the OT profession. Two statements reported $100 \%$ of PTs recording false. They included OTs expect too much of the PT profession and OTs have a higher status than PTs. Responses are illustrated in Table 12 and Table 13. 
Table 12

Frequencies of True and False Responses by OTs Regarding the PT Profession ( $n=182$ )

TRUE FALSE

SECTION II Statements

Physical therapists are competent

n $\%$ n $\%$

$\begin{array}{llll}103 & 97.2 & 3 & 2.8\end{array}$

Physical therapists have very little autonomy

$\begin{array}{llll}4 & 3.8 & 102 & 96.2\end{array}$

Physical therapists understand the capabilities of occupational therapists

$\begin{array}{llll}40 & 37.7 & 66 & 62.3\end{array}$

Physical therapists are highly concerned with the welfare of the patient

$\begin{array}{llll}99 & 93.4 & 7 & 6.6\end{array}$

Physical therapists sometimes encroach on occupational therapy professional territory

$\begin{array}{llll}86 & 81.1 & 20 & 18.9\end{array}$

Physical therapists are highly ethical

$\begin{array}{llll}90 & 84.9 & 16 & 15.1\end{array}$

Physical therapists expect too much of the occupational therapy profession

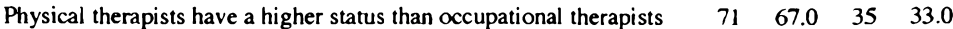

Physical therapists are very defensive about their professional prerogatives

Physical therapists trust occupational therapists' judgment

$\begin{array}{llll}64 & 60.4 & 42 & 39.6\end{array}$

Physical therapists seldom ask occupational therapists' professional advice

Physical therapists fully utilize the capabilities of occupational therapists

Physical therapists do not cooperate well with occupational therapists

$19 \quad 17.9 \quad 87$

82.1

Physical therapists are well trained

$\begin{array}{llll}104 & 98.1 & 2 & 1.9\end{array}$

Physical therapists have good relations with occupational therapists

$\begin{array}{llll}87 & 82.1 & 19 & 17.9\end{array}$ 
Table 13

Frequencies of True and False Responses by PTs Regarding the OT Profession $(n=182)$

TRUE FALSE

SECTION I Statements

Occupational therapists are competent

n $\quad \% \quad$ n $\%$

$\begin{array}{llll}75 & 98.7 \quad 1 & 1.3\end{array}$

Occupational therapists have very little autonomy

$\begin{array}{llll}23 & 30.3 & 53 & 69.7\end{array}$

Occupational therapists understand the capabilities of physical therapists

$\begin{array}{llll}62 & 81.6 & 14 & 18.4\end{array}$

Occupational therapists are highly concerned with the welfare of the $\begin{array}{lllll}76 & 100 & 0 & 0\end{array}$ patient

Occupational therapists sometimes encroach on physical therapy professional territory

$\begin{array}{llll}51 & 67.1 & 25 & 32.9\end{array}$

Occupational therapists are highly ethical

$\begin{array}{llll}73 & 96.1 & 3 & 3.9\end{array}$

Occupational therapists expect too much of the physical therapy profession

$\begin{array}{llll}0 & 0 & 76 & 100\end{array}$

Occupational therapists have a higher status than physical therapists $\quad \begin{array}{lllll}0 & 0 & 76 & 100\end{array}$

$\begin{array}{lllll}\text { Occupational therapists are very defensive about their professional } & 31 & 40.8 & 45 & 59.2\end{array}$ prerogatives

Occupational therapists trust physical therapists' judgment

$\begin{array}{llll}70 & 92.1 & 6 & 7.9\end{array}$

Occupational therapists seldom ask physical therapists' professional advice

$\begin{array}{llll}13 & 17.1 & 63 & 82.9\end{array}$

Occupational therapists fully utilize the capabilities physical therapists

$\begin{array}{llll}34 & 44.7 & 42 & 55.3\end{array}$

Occupational therapists do not cooperate well with physical therapists

$\begin{array}{llll}7 & 9.2 & 69 & 90.8\end{array}$

Occupational therapists are well trained

$\begin{array}{llll}68 & 89.5 & 8 & 10.5\end{array}$

Occupational therapists have good relations with physical therapists

$\begin{array}{llll}68 & 89.5 & 8 & 10.5\end{array}$ 


\section{Frequencies of General Comments}

The third and final part of the survey included an optional general comments section to fill in asking for feedback regarding any important issues, which may have been omitted, or general comments to help the examiner for future use. Seventy-two of the surveys contained additional comments. There were 42 OTs and 30 PTs that provided additional information. Some of these comments will be referenced in the discussion section of this study.

Independent Sample T-Tests

Independent sample t-tests were conducted to examine if any significant mean differences existed between OTs and PTs in relation to the research questions addressed in this study. Table 14 summarizes the results of the $t$-tests. Favorable responses have also been illustrated in Table 15 outlining the frequency of percentages of favorable responses indicated by OTs and PTs for the second part of the survey involving the adapted portion of the IPS. 
Table 14

Mean and Standard Deviations for Interprofessional Issues and Practice Issues of OTs and PTs Regarding Research Questions $(n=182)$

\begin{tabular}{|c|c|c|c|c|c|c|}
\hline \multirow[b]{2}{*}{ Research Question } & \multicolumn{2}{|c|}{$\begin{array}{l}\text { OCCUPATIONAL } \\
\text { THERAPY }\end{array}$} & \multicolumn{2}{|c|}{$\begin{array}{l}\text { PHYSICAL } \\
\text { THERAPY }\end{array}$} & \multirow[b]{2}{*}{$\underline{\mathrm{t}}$} & \multirow[b]{2}{*}{ p-value } \\
\hline & $\underline{\mathrm{M}}$ & $\underline{\mathrm{SD}}$ & $\underline{\mathbf{M}}$ & $\underline{\mathrm{SD}}$ & & \\
\hline $\begin{array}{l}\text { Is there a difference } \\
\text { between how OT and PT } \\
\text { practitioners view the other } \\
\text { profession on } \\
\text { interprofessional issues? }\end{array}$ & 5.05 & 1.34 & 6.58 & .82 & -8.84 & $.001^{* * *}$ \\
\hline $\begin{array}{l}\text { Is there a difference } \\
\text { between how OT and PT } \\
\text { practitioners view the other } \\
\text { profession on practice } \\
\text { issues? }\end{array}$ & 5.13 & 1.74 & 5.70 & 1.47 & -2.30 & .105 \\
\hline $\begin{array}{l}\text { Is there a difference } \\
\text { between how OT and PT } \\
\text { practitioners view OT on } \\
\text { interprofessional issues? }\end{array}$ & 6.60 & 0.73 & 6.58 & 0.82 & 0.22 & .577 \\
\hline $\begin{array}{l}\text { Is there a difference } \\
\text { between how OT and PT } \\
\text { practitioners view OT on } \\
\text { practice issues? }\end{array}$ & 6.30 & 1.29 & 5.70 & 1.47 & 2.94 & .182 \\
\hline $\begin{array}{l}\text { Is there a difference } \\
\text { between how OT and PT } \\
\text { practitioners view PT on } \\
\text { interprofessional issues? }\end{array}$ & 5.05 & 1.34 & 6.01 & 1.13 & -5.12 & $.023 *$ \\
\hline $\begin{array}{l}\text { Is there a difference } \\
\text { between how OT and PT } \\
\text { practitioners view PT on } \\
\text { practice issues? }\end{array}$ & 5.13 & 1.74 & 5.84 & 1.51 & -2.86 & .156 \\
\hline
\end{tabular}

Note. All t-tests statistically significant at $\mathrm{p}<.05$

${ }^{*} \mathrm{p}<.05 .{ }^{* * *} \mathrm{p}<.001$. 
Table 15

Percent of Favorable Responses to Items on the Adapted Portion of the IPS

Regarding OT Regarding PT

IPS Items

$\begin{array}{cccc}\begin{array}{c}\text { OTs } \\ (n=106)\end{array} & \begin{array}{c}\text { PTs } \\ (n=76)\end{array} & \begin{array}{c}\text { OTs } \\ (n=106)\end{array} & \begin{array}{c}\text { PTs } \\ (\mathrm{n}=76)\end{array} \\ 97.2 & 98.7 & 97.2 & 97.4\end{array}$

Are competent ${ }^{\mathrm{a}}$

$\begin{array}{llll}85.8 & 69.7 & 96.2 & 90.8\end{array}$

Understand the capabilities of other profession ${ }^{\mathrm{a}}$

$92.5 \quad 81.6 \quad 37.7 \quad \cdot 71.1$

Are highly concerned with the welfare of the patient $^{\mathrm{a}}$

$\begin{array}{llll}99.1 & 100.0 & 93.4 & 98.7\end{array}$

Sometimes encroach on other professional territory

$\begin{array}{llll}38.7 & 32.9 & 18.9 & 46.1\end{array}$

Are highly ethical ${ }^{\mathrm{a}}$

$\begin{array}{llll}95.3 & 96.1 & 84.9 & 94.7\end{array}$

Expect too much of other profession ${ }^{b}$

$\begin{array}{llll}97.2 & 100.0 & 96.2 & 96.1\end{array}$

Have a higher status than other profession ${ }^{\mathrm{a}}$

$\begin{array}{llll}98.1 & 100.0 & 33.0 & 55.3\end{array}$

Are very defensive about their professional prerogatives $^{\mathrm{b}}$

$\begin{array}{llll}54.7 & 59.2 & 51.9 & 59.2\end{array}$

Trust other professionals' judgment ${ }^{\mathrm{a}}$

$\begin{array}{llll}89.6 & 92.1 & 60.4 & 85.6\end{array}$

Seldom ask other professionals' advice ${ }^{b}$

$\begin{array}{llll}96.2 & 82.9 & 56.6 & 72.4\end{array}$

Fully utilize the capabilities of other profession ${ }^{b}$

67.0

44.7

$29.2 \quad 40.8$

Do not cooperate well with other profession ${ }^{b}$

98.

90.8

82.1

89.5

Are well trained ${ }^{a}$

88.7

89.5

98.1

98.7

Have good relations with other profession ${ }^{b}$

92.5

89.5

82.1

89.5

Note. Interprofessional issue items

${ }^{b}$ Practice issue items 
Question One: Difference in View of Other Profession on Interprofessional Issues

An independent samples t-test comparing the mean scores of OT and PT responses in relation to how each views the other profession on interprofessional issues found a significant difference between the means of the two groups. OTs and PTs differed on how they view the other profession on interprofessional issues $(t=-8.84 ; p<$ $.001)$. PTs had a more favorable view $(\mathrm{m}=6.60, \mathrm{sd}=.82)$ of OT than OTs expressed toward PT $(\mathrm{m}=5.05, \mathrm{sd}=1.34)$. Examination of the individual interprofessional items indicated that perception of status differences between professions was evident, with only $33 \%$ of OTs reporting that PTs did not have a higher status than OTs, but all $100 \%$ of PTs stating false to the statement indicating OTs have a higher status than PTs. A second finding of the individual items revealed that only $38 \%$ of OTs felt that PTs did not understand the capabilities of the OT profession; however, $82 \%$ of PTs indicated that OTs did not understand the capabilities of PT. Regarding trusting professional judgment, $92 \%$ of PTs indicated that OTs trusted the professional judgment of PTs, but $60 \%$ of OTs felt that PTs trust the professional judgment of OTs. Table 15 reports these findings. Question Two: Difference in View of Other Profession on Practice Issues

An independent samples t-test was calculated comparing the mean scores of OT and PT responses in relation to how each views the other profession on practice issues . OTs and PTs did not differ significantly on how they view the other profession on practice issues $(t=-2.30 ; p=.105)$. The mean of the OT responses $(m=5.13, s d=1.74)$ was not significantly different from the mean of the PT responses $(m=5.70, s d=1.47)$ 
Question Three: Differences in View of OT on Interprofessional Issues

An independent samples t-test was calculated comparing the mean scores of OT and PT responses in relation to how each views OT on interprofessional issues. No significant difference was found $(t=0.22, p=.577)$. The mean of the OT responses $(\mathrm{m}=$ $6.60, \mathrm{sd}=0.73)$ was not significantly different from the mean of the PT responses $(\mathrm{m}=$ $6.58, s d=0.82)$.

\section{Question Four: Differences in View of OT on Practice Issues}

An independent samples t-test was calculated comparing the mean scores of OT and PT responses in relation to how each views OT on practice issues. OTs and PTs did not differ significantly on how they view OT on practice issues $(t=2.94, \mathrm{p}=.182)$. The mean of the OT responses $(\mathrm{m}=6.30, \mathrm{sd}=1.29)$ was not significantly different from the mean of the PT responses $(\mathrm{m}=5.70, \mathrm{sd}=1.47)$.

Question Five: Differences in View of PT on Interprofessional Issues

An independent samples t-test comparing the mean scores of OT and PT responses in relation to how each views PT on interprofessional issues found a significant difference between the means of the two groups. OTs and PTs differed on how they view PT on interprofessional issues $(t=-5.12 ; \mathrm{p}<.05)$. PTs had a more favorable view $(\mathrm{m}=6.01, \mathrm{sd}=1.13)$ of their own profession than OTs expressed toward PT $(m=5.05, s d=1.34)$. Understanding the capabilities of the other profession was an item found to be significantly different. Seventy-one percent of PTs reported PTs understand the capabilities of OTs, but only 38\% percent of OTs indicated PTs understand the capabilities of OTs. 


\section{Question Six: Differences in View of PT on Practice Issues}

An independent samples t-test was calculated comparing the mean scores of OT and PT responses in relation to how each views PT on practice issues. OTs and PTs did not differ significantly on how they view PT on practice issues $(t=-2.86 ; p=.156)$. The mean of the OT responses $(\mathrm{m}=5.13, \mathrm{sd}=1.74)$ was not significantly different from the mean of the PT responses $(m=5.84, s d=1.51)$.

\section{Reliability of the IPS Scale}

The internal consistency estimate of reliability, coefficient alpha, was computed for the adapted portion of the Interprofessional Perception Scale. Reverse scoring of nonfavorable item scores was conducted. These items consisted of questions $2,5,7,8,9,11$, and 13 for sections I and II of the IPS. The greater the consistency in responses among items, the higher coefficient alpha was. A value for coefficient alpha $>.5$ indicates satisfactory reliability. Please see Table 16. Areas with reliability coefficients $<.5$ may be a result of the equivalency assumption being violated. Thus internal consistency estimates tend to underestimate reliability. 
Table 16

Results of Coefficient Alpha Among IPS Items

IPS SCALE ITEMS

All items in own

profession

Interprofessional items in

own profession

Practice items in own

profession

All items not in your own

profession

Interprofessional items not

in your own profession

Practice items not in your own profession
OCCUPATIONAL PHYSICAL

THERAPY

THERAPY

.5544

.6659

.6229

.3547

5336

.4577

.4621

.5164

.4858

.7701

.6308

.7481

.6207

.5566

.5207

.6047

.6775

.4781

Note. A value for coefficient alpha $>.5$ indicates satisfactory reliability. 


\section{Chapter V}

\section{Discussion}

The purpose of this study was to examine interprofessional perceptions of OT and PT practitioners. Specifically, to compare interprofessional perceptions that might serve as barriers to effective interdisciplinary team cooperation. If professionals from two, closely aligned, disciplines agree that there is a problem in a given area, this agreement may start the process of problem solving. However, if only one of the professions acknowledges a problem and not the other, any method to resolve the problem would be difficult. This study was based on the idea that differences in perceptions between disciplines can cause barriers that interfere with effective interdisciplinary team functioning. This study reveals differences in interprofessional perceptions between OTs and PTs that may undermine interdisciplinary cooperation between these two disciplines.

\section{Significant Results for Research Questions}

Significant results were found for interprofessional issues in regards to how therapists view the other discipline. Differences in perceptions for interprofessional issues were also found when therapists from each profession were asked to give their views of PT. There were no significant findings found when therapists from each profession were asked to give their views of OT. No significant results were found in any research questions related to practice issues.

The fact that significant results were found on interprofessional issues for two research questions in this study may indicate that both OTs and PTs in this study have differences in perceptions that may be generalized to other OTs and PTs. Both 
disciplines appear to disagree upon a number of attributes that either characterize their own profession or the other profession.

\section{Understanding the Capabilities of Each Profession}

Reviewing data from this study, a number of results that should be of particular concern to OTs and PTs are shown. For example, PTs (71\%) perceive themselves as understanding the capabilities of OT, but significantly fewer OTs (38\%) agree that PTs understand the capabilities of OT. The fact that $43 \%$ of OTs did not consider that PTs understand the capabilities of the OT profession may be problematic. This presents a misunderstanding that can cause misinterpretation in role delineation amongst other things. Both OTs and PTs made comments in regard to a lack of understanding of the other profession. One OT states, "PTs feel OTs are not knowledgeable and thus take on the OT role...feel that OT and PT need to be educated on each other's profession". Another OT responds, "OT needs to educate PT on OT roles in different settings." PTs feel similarly stating, "the definition for OT needs to be made clear to the public," and "PTs need to learn more about OTs wholistic approach.... and sensorimotor".

\section{Trusting Professional Judgment}

One of the most striking aspects of this study was the difference in perceptions regarding trusting the other discipline's professional judgment. PTs (92\%) feel OTs trust PT's professional judgment as opposed to OTs (60\%) indicating PTs that trust OT's professional judgment. Rothberg (1981) states, "Perhaps the single overriding factor interfering with the smooth functioning of a multidisciplinary team is a lack of trust in the professional judgment of members of other disciplines" (p. 409). 


\section{$\underline{\text { Status Differences }}$}

Results indicate both PTs and OTs indicate that PTs have a higher status than OTs. This can interfere with effective cooperation between both disciplines, as one discipline may feel inferior to the other. One OT comments, "The higher status of PTs is one of the biggest problems". She also states, "...this is a result of better reimbursement (for PTs)". If this should be one of the contributing factors to status differences, perhaps an increased awareness on this issue is needed by OTs.

\section{Encroachment on Professional Territory}

Although it is not an interprofessional issue, another area of concern is role conflict characterized by feelings of encroachment upon one's own professional territory by another discipline. One respondent indicates, "both professions have contributed to encroachment...PT education has begun to include cognitive and perceptual components outside their original purpose of using physical agents to address physical skills... OT education has begun to include fragmented skills rather than an occupational focus." Since both OTs and PTs regard such areas as physical agent modalities and ADLs as part of their professional domain, it is not surprising that there were perceived differences regarding encroachment. Eighty-one percent of OTs felt PTs sometimes encroach on OTs' professional territory, however only 54\% PTs felt that PTs sometimes encroach on OTs' domain. Conversely, $67 \%$ of PTs express the view OTs sometimes encroach upon PTs' territory, compared to $61 \%$ of OTs who agreed that OTs sometime encroach. However, encroachment is not viewed negatively by all, as several OTs and PTs commented. One OT states, "both OT and PT work together to treat the whole patient so encroachment is present but for the good of the patient". A PT comments, "With good 
communication, the overlap of boundaries can really work towards the patient's benefits."

\section{Professional Training}

Although the focus of this study was on differences in perception between OTs and PTs, some areas without statistically significant differences are worthy of examination because they suggest OTs need to reflect upon their own opinion of themselves as professionals. For example, $98 \%$ of OTs indicated that PTs are well trained, but only $89 \%$ of OTs agreed that OTs are well trained. This was also made apparent in such comments made by OTs as, "OT education is too general", "essentials are so minimal there is a drastic difference in skills of each school's graduates", and "it is disappointing that the OT education level of entry level master's degree graduates is often less than entry level bachelor's degree graduates".

\section{Most Serious Problem Facing Effective Team Functioning}

A significant difference in responses between therapists was reported when asked to indicate the most serious problem effecting interdisciplinary team function. The therapists were given the choices of encroachment problems, ethical problems, competency problems, and other to choose from. OTs (43\%) responded that encroachment problems presented the most serious problem as opposed to $42 \%$ of PTs who indicated competency as the most serious problem. This presents an important issue that OTs and PTs hold different views in identification of interprofessional problems. This difference might be interpreted that PTs do not perceive that OTs have knowledge in specific areas to base competency. It also may be that competency is viewed as a more relevant problem by PTs due to the PTs holding a specialization, suggesting a bias of the 
sample. On the other hand, OTs may view the most serious problem in a less specific category, such as encroachment. Results found in this area should not be interpreted lightly. Further examination of this area should be conducted by the reader and additional research defining the most serious problem(s) could warrant additional results. Educational Methods Influential in Addressing Problems Between Professions

Both professions felt the most influential educational method in addressing problems between the two professions would be to increase the amount of collaboration during professional training prior to receiving degree/certification/licensure. Sutherland and Fulton (1988) share this view and note that progress towards interdisciplinary teams may require education that uses an interdisciplinary approach in learning. In a study by Tryssenaar et al (1996) addressing interdisciplinary educational activities in OT and PT programs in Canada, results indicated that interdisciplinary activities are now encouraged and many programs had hoped to expand in the future. "Through a structured interdisciplinary educational opportunity, medical, occupational therapy and physical therapy students learned to interact with each other and began to gain an appreciation of each other's discipline." (MacKinnon and MacRae, 1996, p. 47)

\section{Encouraging Results}

Many aspects of this study identify problems associated with OTs' and PTs' views of each other and their own professions; however some results are encouraging and should not be overlooked. It is important to recognize that among the OTs and PTs in the profession for ten years or more, neither felt a lack of interdisciplinary team functioning has become more of a problem. As seen in Table 15, 97\% of OTs indicated that they consider PTs to be competent professionals, and an even higher percentage of PTs (99\%) 
view OTs as competent. Ninety three percent of OTs regard PTs as being highly concerned with the welfare of the patient, and $100 \%$ of PTs indicated OTs as highly concerned. Only $4 \%$ of OTs reported they felt PTs expect too much of them, and no PTs (0\%) felt OTs expect too much of them. Perhaps agreement in these areas can foster the communication that is needed to embark upon improving more problematic areas between these two professions. Particularly of interest, is both professions concern about the welfare of the patient or client because the goal of OT and PT is to meet the needs of those they serve (Moyers, 1999, APTA, 1999) Focusing on the welfare of the client, therefore, could provide a stepping stone towards improved collaboration and interdisciplinary team functioning.

\section{Recommendations for Future Research}

Many areas could be recommended for future research to continue to investigate interprofessional issues between OTs and PTs. Additional studies could look at the relationship between OT and PT students. Research could be conducted to assess their views of each other, possibly indicating that perceptions are already formed or not formed prior to entering the work environment. This may suggest that the educational process may or may not play a role in developing these beliefs.

Additional studies could also be conducted addressing effective interdisciplinary educational methods that are successful in fostering effective interdisciplinary roles among professionals. This study suggests that increasing the amount of collaboration during professional training prior to receiving degree/certification/licensure would be the most influential educational method. 
Although not specific to this study, interesting feedback was obtained from both PTs and OTs providing topics that could warrant additional investigations. One of these topics suggests looking at the role administration plays in contributing to an interdisciplinary work environment in different settings. One OT suggests, "Relations between the two (OTs and PTs) are dependent upon administrative structure. Good interdisciplinary relations filter down from the top." A PT comments, "Administration can help promote collaboration or discourage it between team members by physical location, (of staff) promoting or discouraging co-treatments and/or team building." Another topic repeated several times in the respondent's comments addressed that certain settings contribute to more or less effective interdisciplinary functioning in the workplace. For example, many pediatric therapists from both disciplines indicated better collaboration with each other in comparison to other therapists in different settings. Research could investigate further the dynamics of this occurrence and potentially outline the elements to this success.

Finally, the role of reimbursement and insurance issues was mentioned numerous times in comments by both disciplines. It appears that different insurance providers cover certain services. This may not allow one profession or the other to provide what may seem to be the treatment needed. Thus, encroachment is occurring between both professions in order to better meet the needs of the client. Additional research could provide solutions to these important issues and in return may help to improve collaboration between both professions. 


\section{Summary}

Overall, this study showed that potential barriers to interdisciplinary team functioning exist between OTs and PTs, specifically regarding interprofessional issues. These areas include: understanding the capabilities of the other profession, trusting the other's judgment, and status differences. Although significant results were not found in regards to practice issues, both professions expressed many concerns regarding encroachment. Educational methods to help resolve such barriers were identified, with increasing the amount of collaboration during professional training indicated as the most influential.

Some of the results of this study were encouraging, with competency and concern for the welfare of the client, being among two of these results. Several therapists also commented in a positive regard, stating that therapists of both professions do work collaboratively.

Ultimately, effective interdisciplinary team functioning lies personally with each OT and PT. With an increased awareness of potential barriers that may disrupt this pursuit, the individual therapist can be better prepared to work successfully through these issues and work towards the common goal of both professions. That goal being to meet the needs of the client. This study was intended to help identify those barriers. In doing so, the next step is for the therapist to acknowledge these barriers and to work together in a collaborative manner with each profession to overcome. 


\section{$\underline{\text { References }}$}

Abreu, B. C. (1997, March). Interdisciplinary leadership: The future is now. OT Practice, 20-25.

American Occupational Therapy Association. (February, 1999). Definition of OT practice for the AOTA Model Practice Act, adopted 2/8/99. Bethesda, MD: Author.

American Occupational Therapy Association. (1997). Bylaws. Article III, Section 1. Bethesda, MD: Author.

American Physical Therapy Association (1999). A guide to physical therapist practice, part 1 (Section 1, p.2). Alexandria, VA: Author..

Brown, G. T., \& Greenwood, J. (1998). Occupational therapy and physiotherapy: Similar, but separate. British Journal of Occupational Therapy, 62(4), 163-170.

Ducanis, A. J. \& Golin, A. K. (1979). Interprofessional relationships. In The interdisciplinary health care team: A handbook (pp.31-53). Germantown, MD: Aspen Systems Corporation.

Engel, G. L. (1980). The clinical application of the biopsychosocial model. American Joumal of Psychiatry, 137(5), 535-544.

Foto, M. (1998, May). Professional evolution: Should health care environmental changes force OT and PT practice into a new delivery model? OT Practice, 23-25.

Golledge, J. (1998, April). Distinguishing between occupation, purposeful activity and activity, part 1: Review and explanation. British Journal of Occupational Therapy, 61(3), 100-105.

Hewstone, M., Stroebe, W., Codol, J., and Stephen, G. (1988). Introduction to social psychology. A European perspective. New York, NY: Basil Blackwell Inc.

Hubbard, S. (1991). Towards a truly holistic approach to occupational therapy. British Journal of Occupational Therapy, 54(11), 415-418.

Kamps, J., Page, R., Seagrave, C., Sweet, M., Zettergren, K., \& MacKinnon, J. (1996). Stereotypes between physical and occupational therapy students. Joumal of Physical Therapy Education, 10(1), 18-21. 
Kielhofner, G. \& Nicol, M. (1989). The model of human occupation: A developing conceptual tool for clinicians. British Joumal of Occupational Therapy, 52(6), 210-214.

Klein, J. T. (1990). Interdisciplinarity: History, theory, and practice. Detroit, MI: Wayne State University Press.

Koepp-Baker, H. (1979). The craniofacial team. In Kenneth R. Bzoch (Ed.), Communicative disorders related to cleft lip and palate (pp.54). Boston, MA: Little-Brown.

Laing, R. D., Phillipson, H., \& Lee, A. R. (1966) Interpersonal perception: A theory and a method of research. New York, NY: Harper and Row.

Liston, C., \& Docking, R. (1985). Some strategies for conflict resolution: Physiotherapy/Occupational therapy liaison. Physiotherapy Practice, 1(2), 93-98.

MacKinnon, J. L., \& MacRae, N. (1996). Fostering geriatric interdisciplinary collaboration through academic education. Physical and Occupational Therapy in Geriatrics, 14(3), 41-49.

Morris, H. L. (1980). The structure and function of interdisciplinary health teams. In Carlos F. Salina \& Ronald J. Jorgenson (Eds.), Dentistry in the interdisciplinary treatment of genetic diseases (pp.109). New York, NY: Alan R. Liss.

Moyers, P.A. (1999). The guide to occupational therapy practice. American Occupational Therapy Association. American Journal of Occupational Therapy, 53(3), 247-322.

Parker, H. J. \& Chan, F. (1986a) Prestige of allied health professions: Perceptions of occupational and physical therapists. Occupational Therapy Journal of Research. 6. 245-250.

Parker, H. J. \& Chan, F. (1986b, May). Stereotyping: Physical and occupational therapists characterize themselves and each other. Physical Therapy, 66(5), 668 672.

Peck, E. \& Norman, I. J. (1999, June). Working together in adult community mental health services. Exploring inter-professional role relations. Journal of Mental Health, 8(3), 231-244.

Rothberg, J. S. (1981). The rehabilitation team: Future direction. Archives of Physical Medicine and Rehabilitation, 62, 407-410. 
Smith, R. W., \& Lay, C. (1991, October). Preventing or eliminating barriers to interdisciplinary treatment. Paper presented at the 1991 American Therapeutic Recreation Association Annual Conference, Spokane, WA.

Smith, R.W., Perry, T.L., Neumayer, R. J., Potter, J. S., \& Smeal, T. M. (1992). Interprofessional perceptions between therapeutic recreation and occupational therapy practitioners: Barriers to effective interdisciplinary team functioning. Therapeutic Recreation Journal, 26(4), 31-42.

Strasser, D. C., Falconer, J. A., \& Martino-Saltzmann, D. (1994, February). The rehabilitation team: Staff perceptions of the hospital environment, the interdisciplinary team environment, and interprofessional relations. Archives of Physical Medicine and Rehabilitation, 75(2), 177-182.

Streed, C. P., \& Stoecker, J. L. (1991, January). Stereotyping between physical therapy students and occupational therapy students. Physical Therapy, 71(1), 16-20.

Sutherland R. W. \& Fulton, M.J. (1988). Health Care in Canada. Ottawa, ON: The Health Group.

Tamm, M. E. (1993). Models of health and disease. British Journal of Medical Psychology, 66, 213-228.

Thomas, C. L. (Ed.). (1997). Taber's cyclopedic medical dictionary. (18 ${ }^{\text {th }}$ ed.). Philadelphia: F.A. Davis Company.

Tryssenaar, J., Perkins, J., \& Brett, L. (1996, October). Undergraduate interdisciplinary education: Are we educating for future practice? Canadian Journal of Occupational Therapy, 63(4), 245-251.

Whitehouse, F. A. (1951). Teamwork: A democracy of professions. Exceptional Children, 18, 45-46.

Yerxa, E.J. (1995). Who is the keeper of occupational therapy's practice and knowledge? American Journal of Qccupational Therapy, 49(4), 295-299. 
Appendix 
September 17, 2001

Dear Therapist,

As a member of the field of occupational and/or physical therapy, you may have heard about problems, such as encroachment, levels of competency, or others related to interdisciplinary team functioning. In order to begin to work on these problems it is important to identify differences between the way therapists in their own profession view themselves and others outside their profession. It is also important to know how others view your own profession. After identification of problem areas, vital steps can be taken to help solve such problems and promote a healthy and well-balanced working environment amongst professionals.

You have been chosen for a survey project in which individuals are being asked to give their opinion on these matters. In order that the results of this survey reflect the perceptions of individuals within the profession of occupational and/or physical therapy, it is important that each questionnaire be completed. Please return your completed questionnaire, no later than Monday, October 15th to:

\section{Jennifer Gober}

Miami, FL 33138

A stamped envelope with this address information has been enclosed for your convenience.

There are no reasonably foreseeable risks or discomforts in participating. You may be assured of complete confidentiality. Your name will never be placed on the questionnaire itsclf.

Your completion of this survey indicates your willingness to participate in this study.

I would be happy to answer any questions you may have about this study. Please write, email, or call me at 305-759-7673. My faculty supervisor, Dr. Kaplan, can also be contacted at 305-348-3105.

Thank you very much for your assistance.

Sincerely,

Jennifer Gober

Project Director

Professional Master Student in Occupational Therapy at Forida International University 


\section{Research Survey for OTs}

RESPONDENT DATA: ALl ANSWERS ARE CONFIDENTIAL. PLEASE DO NOT SIGN THIS FORM. PLEASE COMPLETE ALL QUESTIONS. PLEASE CHOOSE ONE BEST ANSWER TO MATCH THE CRITERIA.

1. What is your present profession? (Please circle the number of your response)

$\begin{array}{ll}1 & \text { OCCUPATIONAL THERAPIST } \\ 2 & \text { PHYSICAL THERAPIST } \\ 3 & \text { BOTH } \\ 4 & \text { NEITHER }\end{array}$

IF YOUR RESPONSE TO QUESTION 1. WAS "BOTH" OR "NEITHER" PLEASE STOP HERE AND RETURN YOUR QUESTIONNAIRE IN THE STAMPED ENVELOPE PROVIDED.

2. What is your present age? (Please circle the number of your response.)

$\begin{array}{ll}1 & \text { 25 YEARS AND UNDER } \\ 2 & 26-35 \text { YEARS } \\ 3 & 36-45 \text { YEARS } \\ 4 & 46-55 \text { YEARS } \\ 5 & 56-65 \text { YEARS } \\ 6 & \text { OVER 65 YEARS }\end{array}$

3. What is your gender? (Please circle the number of your response.)

1 MALE

4. How many years of experience do you have practicing in your current profession? (Please circle the number of your response.)

$\begin{array}{ll}1 & 0-5 \text { YEARS } \\ 2 & 6-10 \text { YEARS } \\ 3 & 11-15 \text { YEARS } \\ 4 & 16-20 \text { YEARS } \\ 5 & 21-25 \text { YEARS } \\ 6 & \text { MORE THAN } 25 \text { YEARS }\end{array}$

5. What is the specialty area that you work primarily in? (Please circle the number of your response.)

Please remember to choose the one best answer.

\begin{tabular}{ll}
1 & SCHOOL SYSTEMS \\
2 & PEDIATRICS \\
3 & EDUCATION (PROGRAM DIRECTOR, FACURTY AND FIELDW'ORK COORDINATOR) \\
4 & GERIATRICS \\
5 & HOME AND COMMINITY HEALTH \\
6 & MENTAL HEALTH \\
7 & PHYSICAL DISABILITIES \\
8 & HAND THERAPY' \\
9 & TECHNOLOGY' \\
10 & WORK PROGRAMS \\
11 & OTHER (Please fill in) \\
\hline
\end{tabular}


6. What is the highest degree you have earned? (Please circle the number of your response.)

\begin{tabular}{ll}
1 & BACHELOR'S DEGREE \\
2 & MASTER'S DEGREE \\
3 & DOCTORAL DEGREE \\
4 & OTHER (Please fill in) \\
\hline
\end{tabular}

7. Are you a member of an interdisciplinary team at your current place of employment?

$1 \quad$ YES

$2 \quad \mathrm{NO}$

8. In your opinion, which one of the following problems facing effective interdisciplinary team functioning amongst occupational therapists and physical therapists is the MOST serious? (Please circle the number of your response)

\begin{tabular}{ll}
1 & ENCROACHMENT PROBLEMS \\
2 & COMPETENCY PROBLEMS \\
3 & ETHICAL PROBLEMS \\
4 & OTHER (Please fill in) \\
\hline
\end{tabular}

9. Would you say that the lack of effective interdisciplinary team functioning seen amongst occupational therapists and physical therapists is more, about the same, or less of a problem than it was 10 years ago? (Please circle the number of your response)

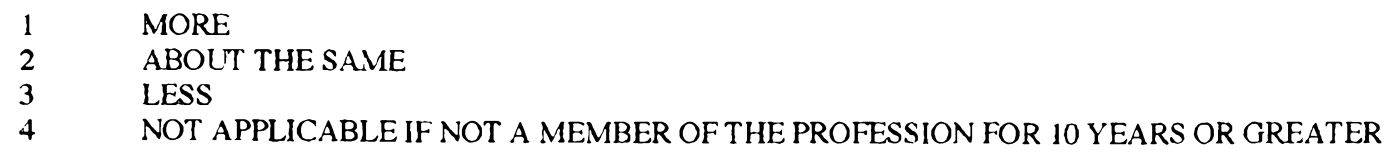

10. In your opinion, what educational methods would be the most, second, and third most influential in addressing problems between occupational therapists and physical therapists concerned with effective interdisciplinary team functioning? (Please place the appropriate number in each box.)

Would be:

口MOST

ISECOND

DTHIRD attending on-site staff in-services

participating in interdisciplinary collaboration of educational coursework attending seminars/workshops

practicing simulated exercises during facility orientation

increasing knowledge from reading journal and scholarly publications

increasing amount of collaboration during professional training prior to receiving degree/certification/licensure

Please read the information below before answering any more items.

This is a study of interprofessional perceptions. It is intended to look at some of the ways various professions view each other

In answering the following items, do not spend too much time on any one statement. Your first impression is what we want. Please answer with as much candor as pussible. Answer each question as you proceed. Each page should take only about 2-3 minutes. Please answer each item.

As you look at the following page, you will see that in Column I you should indicate whether you think the statement is true or false. The first section looks at how you view your own profession. The second section looks at how you view the other's profession. Please place an $X$ to indicate your answers.

In order to help the responder understand in what manner he'she should respond, a brief statement is addressed at the top of each page. Plcase read carclully and do not omit any answers.

You may begin now. 


\section{SECTION I:}

Answer the following items in relation to Your Own Profession:

\section{Persons in Occupational Therapy:}

1. Occupational therapists are competent

2. Occupational therapists have very little autonomy

3. Occupational therapists understand the capabilities of physical therapists

4. Occupational therapists are highly concerned with the welfare of the patient

5. Occupational therapists sometimes encroach on physical therapy professional territory

6. Occupational therapists are highly ethical

7. Occupational therapists expect too much of the physical therapy profession

8. Occupational therapists have a higher status than physical therapists

9. Occupational therapists are very defensive about their professional prerogatives

10. Occupational therapists trust physical therapists' judgment

11. Occupational therapists seldom ask physical therapists' professional advice

12. Occupational therapists fully utilize the capabilities physical therapists

13. Occupational therapists do not cooperate well with physical therapists

14. Occupational therapists are well trained

15. Occupational therapists have good relations with physical therapists
Column I

How Would You As an

Occupational Therapist Answer?

TRUE

FALSE

$\square$

$\square$

$\square$

$\square$

$\square$

$\square \square$

$\square$

$\square$

$\square$

$\square$

$\square$

$\square$

$\square$

$\square$

$\square$ $\square$

$\square$

$\square$

$\square$

$\square$

$\square$

$\square$

$\square$

$\square$

D

D

$\square$

$\square$

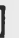

(

\section{(}

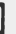

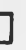

]

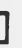

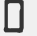


SECTION: II

Answer the following items in relation to the profession that is "NOT" your own:

Persons in Physical Therapy:

\section{Column I}

How Would You As an

Occupational Therapist Answer?

TRUE

FALSE

1. Physical therapists are competent

2. Physical therapists have very little autonomy

3. Physical therapists understand the capabilities of occupational therapists

4. Physical therapists are highly concerned with the welfare of the patient

5. Physical therapists sometimes encroach on occupational therapy professional territory

6. Physical therapists are highly ethical

7. Physical therapists expect 100 much of the occupational therapy profession

8. Physical therapists have a higher status than occupational therapists

9. Physical therapists are very defensive about their professional prerogatives

10. Physical therapists trust occupational therapists' judgment

11. Physical therapists seldom ask occupational therapists' professional advice

12. Physical therapists fully utilize the capabilities of occupational therapists

13. Physical therapists do not cooperate well with occupational therapists

14. Physical therapists are well trained

15. Physical therapists have good relations with occupational therapists

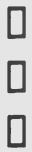

$\square$

口

口

口

D

口

口

$\square$

$\square$

$\square$

$\square$

$\square$<smiles>[CH]</smiles>

口<smiles>[CH]</smiles>

口

口

$\square$

$\square$

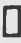

$\square$

口

口

$\square$

$\square$ 
General Comments: (Please provide feedback regarding any important issues which may have been omitted or general comments to help the examiners for future use.)

Please return survey to:

Jennifer Gober, MOTS, CTRS

Miami, FL 33138 


\section{Research Survey for PTs}

RESPONDENT DATA: ALl ANSWERS ARE CONFIDENTIAL. PLEASE DO NOT SIGN THIS FORM. PLEASE COMPLETE ALL QUESTIONS. PLEASE CHOOSE ONE BEST ANSWER TO MATCH THE CRITERIA.

1. What is your present profession? (Please circle the number of your response)

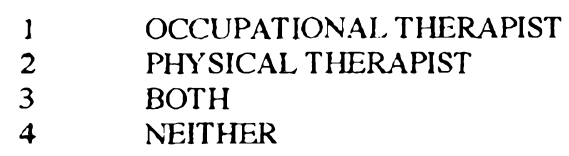

IF YOUR RESPONSE TO QUESTION 1. WAS "BOTH" OR "NEITHER" PLEASE STOP HERE AND RETURN YOUR QUESTIONNAIRE IN THE STAMPED ENVELOPE PROVIDED.

2. What is your present age? (Please circle the number of your response.)

125 YEARS AND UNDER

2 26-35 YEARS

3 36-45 YEARS

$4 \quad 46-55$ YEARS

5 56-65 YEARS

6 OVER 65 YEARS

3. What is your gender? (Please circle the number of your response.)

1 MALE

2 FEMALE

4. How many years of experience do you have practicing in your current profession? (Please circle the number of your response.)

$1 \quad 0-5$ YEARS

2 6-10 YEARS

3 11-15 YEARS

4 16-20 YEARS

$5 \quad 21-25$ YEARS

6 MORE THAN 25 YEARS

5. What is the specialty area that you work primarily in? (Pleasc circle the number of your response.)

Please remember to choose the one best answer.

$\begin{array}{ll}1 & \text { SCHOOL SYSTEMS } \\ 2 & \text { PEDIATRICS } \\ 3 & \text { EDUCATION (PROGRAM DIRECTOR, FACULTY AND HTELDWORK COORDINATOR) } \\ 4 & \text { GERIATRICS } \\ 5 & \text { HOME AND COMMUNITY HEALTH } \\ 6 & \text { MENTAL HEALTH } \\ 7 & \text { PHY SICAL DISABILITIES } \\ 8 & \text { HAND THERAPY } \\ 9 & \text { TECHNOLOGY } \\ 10 & \text { WORK PROGRAMS } \\ 11 & \text { OTHER (Please fill in) }\end{array}$


6. What is the highest degree you have eamed? (Please circle the number of your response.)

\begin{tabular}{ll}
1 & BACHELOR'S DEGREE \\
2 & MASTER'S DEGREE \\
3 & DOCTORAL DEGREE \\
4 & OTHER (Please fill in) \\
\hline
\end{tabular}

7. Are you a member of an interdisciplinary team at your current place of employment?

$\begin{array}{ll}1 & \text { YES } \\ 2 & \text { NO }\end{array}$

8. In your opinion, which one of the following problems facing effective interdisciplinary team functioning amongst occupational therapists and physical therapists is the MOST serious? (Please circle the number of your response)
1 ENCROACHMENT PROBLEMS
2 COMPETENCY PROBLEMS
3 ETHICAL, PROBLEMS
4 OTHER (Please fill in)

9. Would you say that the lack of effective interdisciplinary team functioning seen amongst occupational therapists and physical therapists is more, about the same, or less of a problem than it was 10 years ago? (Please circle the number of your response)

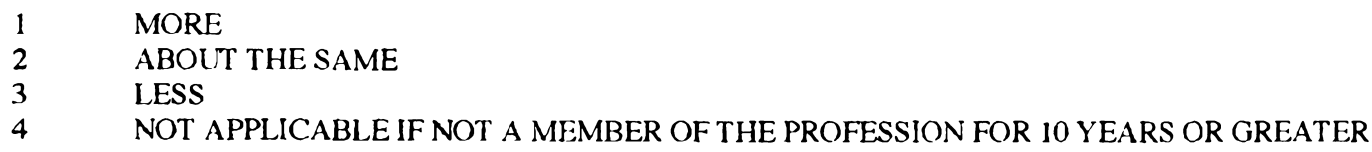

10. In your opinion, what educational methods would be the most, second, and third most influential in addressing problems between occupational therapists and physical therapists concerned with effective interdisciplinary team functioning? (Please place the appropriate number in each box.)

Would be:

[MOST

DSECOND

UTHIRD

\author{
attending on-site staff in-services \\ participating in interdisciplinary collaboration of educational coursework \\ attending seminars/workshops \\ practicing simulated exercises during facility orientation \\ increasing knowledge from reading journal and scholarly publications \\ increasing amount of collaboration during professional training prior to receiving \\ degree/certification/licensure
}

Please read the information below before answering any more items.

This is a study of interprofessional perceptions. It is intended to look at some of the ways various professions view each other.

In answering the following items, do not spend too much time on any one statement. Your first impression is what we want. Please answer with as much candor as possible. Answer each question as you proceed. Each page should take only about 2-3 minutes. Please answer each item.

As you look at the following page, you will see that in Column I you should indicate whether you think the statement is true or false. The first section looks at how you view your own profession. The second section looks at how you view the other's profession. Please place an $X$ to indicate your answers.

In order to help the responder understand in what manner he she should respond, a brief statement is addressed at the top of each page. Please read carefulty and do not omit any answers

You may begin now. 
SECTION 1:

Answer the following items in relation to Your Own Profession:

\section{Persons in Physical Therapy:}

1. Physical therapists are competent

2. Physical therapists have very little autonomy

3. Physical therapists understand the capabilities of occupational therapists

4. Physical therapists are highly concerned with the welfare of the patient

5. Physical therapists sometimes encroach on occupational therapy professional territory

6. Physical therapists are highly ethical

7. Physical therapists expect too much of the occupational therapy profession

8. Physical therapists have a higher status than occupational therapists

9. Physical therapists are very defensive about their professional prerogatives

10. Physical therapists trust occupational therapists' judgment

11. Physical therapists seldom ask occupational therapists' professional advice

12. Physical therapists fully utilize the capabilities of occupational therapists

13. Physical therapists do not cooperate well with occupational therapists

14. Physical therapists are well trained

15. Physical therapists have good relations with occupational therapists
Column I

How Would You As a

Physical Therapist Answer?

TRUE

FALSE

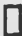

$\square$

$\square$

$\square$

$\square$

$\square$

$\square$

$\square$

$\square$

$\square$

$\square$

$\square$

$\square$

$\square$

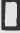

$\square$

$\square$

$\square$

$\square$

$\square$

口

$\square$

D

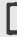

$\square$

D 
SECTION: II

Answer the following items in relation to the profession that is "NOT" your own:

\section{Persons in Occupational Therapy:}

1. Occupational therapists are competent

2. Occupational therapists have very little autonomy

3. Occupational therapists understand the capabilities of pbysical therapists

4. Occupational therapists are kighly concerned with the welfare of the patient

5. Occupational therapists sometimes encroach on physical therapy professional territory

6. Ocxapational therapists are highly ethical

7. Occupational therapists expect too much of the phiysical therapy profession

8. Occupational therapists have a higher status than physical therapists

9. Occupational therapists are very defensive about their professional prerogatives

10. Occupational therapists trust physical therapists' judgment

11. Occupational therapists seldom ask physical therapists' professional advice

12. Occupational therapists fully utilize the capabilities physical therapists

13. Occupational therapists do not cooperate well with physical therapists

14. Occupational therapists are well trained

15. Occupational therapists have good relations with physical therapists

\section{Column I}

How Would You As a

Physical Therapist Answer?

TRUE

FALSE

$\square$

$\square$

$\square$

$\square$

$\square$

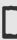

(

口 $\square$

$\square$

○ $\square$

○ $\square$

$\square$

$\square$

$\square$

$\square$ $\square$

D

$\square$

$\square$

$\square$

$\square$

口

$\square$

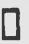

(

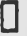

]

]

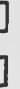

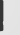

0

$\square$ 
General Comments: (Please provide feedback regarding any important issues which may have been omitted or general comments to help the examiners for future use.)

Please return survey to:

Jennifer Gober, MOTS, CTRS

Miami, FL 33138 


\section{Interprofessional Perception Scale*}

Persons in (identify profession)

Are competent ${ }^{a}$

Have very little autonomy

Understand the capabilities of other profession ${ }^{\mathrm{a}}$

Are highly concerned with the welfare of the patient ${ }^{2}$

Sometimes encroach on other professional territory ${ }^{b}$

Are highly ethical $^{\mathrm{a}}$

Expect too much of other profession

Have a higher status than other profession ${ }^{a}$

Are very defensive about their professional prerogatives ${ }^{b}$

Trust other professionals' judgment ${ }^{\mathrm{a}}$

Seldom ask other professionals' advice ${ }^{b}$

Fully utilize the capabilities of other profession ${ }^{\mathrm{b}}$

Do not cooperate well with other profession ${ }^{b}$

Are well trained ${ }^{a}$

Have good relations with other profession ${ }^{b}$
Favorable Responses

True

False

$\mathrm{X}$

$\mathrm{X}$

$\mathrm{X}$

$\mathrm{X}$

$\mathrm{X}$

$\mathrm{X}$

$\mathrm{X}$

$\mathrm{X}$

$\mathrm{X}$

$\mathrm{X}$

$\mathrm{X}$

$\mathrm{X}$

$\mathrm{X}$

X

$\mathrm{X}$

*Adapted with verbal permission from Ducanis, A.J. \& Golin, A.K. (1979). The interdisciplinary health care team: A handbook (pp.39-40). Germantown, MD: Aspen Systems Corporation.

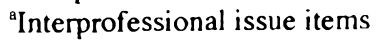

${ }^{\circ}$ Practice issue items 